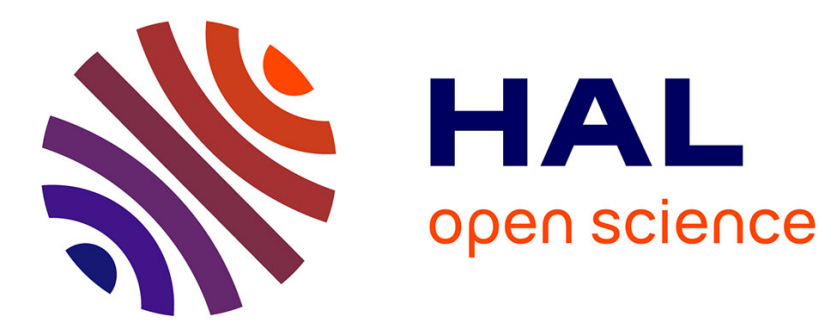

\title{
On gas-liquid intermittent flow in a horizontal pipe: Influence of sub-regime on slug frequency
}

\author{
A. Arabi, Y. Salhi, Y. Zenati, E.K. Si-Ahmed, J. Legrand
}

\section{To cite this version:}

A. Arabi, Y. Salhi, Y. Zenati, E.K. Si-Ahmed, J. Legrand. On gas-liquid intermittent flow in a horizontal pipe: Influence of sub-regime on slug frequency. Chemical Engineering Science, 2020, 211, pp.115251. 10.1016/j.ces.2019.115251 . hal-02548768

\section{HAL Id: hal-02548768 \\ https://hal.science/hal-02548768}

Submitted on 21 Dec 2021

HAL is a multi-disciplinary open access archive for the deposit and dissemination of scientific research documents, whether they are published or not. The documents may come from teaching and research institutions in France or abroad, or from public or private research centers.
L'archive ouverte pluridisciplinaire $\mathbf{H A L}$, est destinée au dépôt et à la diffusion de documents scientifiques de niveau recherche, publiés ou non, émanant des établissements d'enseignement et de recherche français ou étrangers, des laboratoires publics ou privés.

\section{다)(1) $(5$}

Distributed under a Creative Commons Attribution - NonCommerciall 4.0 International 


\title{
On Gas-liquid intermittent flow in a horizontal pipe: Influence of sub-regime on slug frequency
}

\author{
A. ARABI ${ }^{1,2}$, Y. SALHI $^{2}$, Y. ZENATI ${ }^{2}$, E.K. SI-AHMED ${ }^{3,2^{*}}$, J. LEGRAND $^{3}$ \\ ${ }^{1}$ SONATRACH, Direction Centrale Recherche et Développement, Avenue 1er Novembre, 35000, Boumerdes, \\ Algeria. \\ ${ }^{2}$ University of sciences and technology Houari Boumedienne, Physics' Faculty Laboratory of Theoretical and \\ Applied Fluid Mechanics, LMFTA BP 32 El Alia 16111 Bab Ezzouar , Algiers Algeria, \\ ${ }^{3}$ Nantes Université, ONIRIS, CNRS, GEPEA, UMR6144, 37 Bd de l'université BP406, 44602 Saint -Nazaire, \\ France \\ *corresponding author el-khider.si-ahmed@univ-nantes.fr
}




\begin{abstract}
Among the intrinsic parameters identified in intermittent gas-liquid flows; slug frequency is known as the most complicated one to model. The present work concerns the investigation of slug frequency for various sub-regimes which might be found in intermittent flow. Experiments, near atmospheric pressure conditions, were carried out in a 13-meter long horizontal pipe with a $30 \mathrm{~mm}$ inside diameter. The study involved plug regime, less aerated slug and highly aerated slug flows. Comparison between different methods of slug frequency quantification, from pressure drop signal, was performed with counting, Wilkens \& Thomas as well as the Power Spectral Density (PSD) methods. PSD was found to be the best method for slug frequency measurements. A new flow map, using dimensionless numbers as coordinates for the subregimes distinction, was established. After performing substantial comparisons between the present results and models available in the literature a new correlation is proposed including the sub-regime types.
\end{abstract}

Keywords : Gas-liquid two-phase flow, intermittent flow, slug frequency, differential pressure fluctuations. 


\section{Nomenclature}

\begin{tabular}{|c|c|c|}
\hline $\mathrm{d}$ & Difference & \\
\hline $\mathrm{D}$ & Pipe diameter & {$[\mathrm{m}]$} \\
\hline$F_{f}$ & Fanning friction coefficient & {$[-]$} \\
\hline$f$ & Frequency & {$[\mathrm{Hz}]$} \\
\hline $\mathrm{Fr}$ & Froude number & {$[-]$} \\
\hline $\mathrm{g}$ & Gravitationnal acceleration & {$\left[\mathrm{m} \cdot \mathrm{s}^{-2}\right]$} \\
\hline $\mathrm{H}$ & Holdup or Height & {$[-]$} \\
\hline HAS & Highly Aerated Slug & \\
\hline $\mathrm{L}$ & Length & {$[\mathrm{m}]$} \\
\hline LAS & Less Aerated Slug & \\
\hline $\mathrm{N}$ & Number of wave peaks & {$[-]$} \\
\hline $\mathrm{P}$ & Pressure & {$[\mathrm{Pa}]$} \\
\hline PSD & Power Spectral Density & \\
\hline $\mathrm{Q}$ & Volumetric flow rate & {$\left[\mathrm{m}^{3} \cdot \mathrm{s}^{-1}\right]$} \\
\hline $\operatorname{Re}$ & Reynolds number & {$[-]$} \\
\hline St & Strouhal number & {$[-]$} \\
\hline $\mathrm{T}$ & Time serie duration & {$[\mathrm{s}]$} \\
\hline $\mathrm{U}$ & Uncertainty & \\
\hline $\mathrm{V}$ & Velocity & {$\left[\mathrm{m} \cdot \mathrm{s}^{-1}\right]$} \\
\hline $\mathrm{x}$ & Axial coordinates & {$[\mathrm{m}]$} \\
\hline$X$ & Lockhart-Martinelli parameter & {$[-]$} \\
\hline \multicolumn{3}{|c|}{ Greeks letters } \\
\hline$\Delta$ & Differential & \\
\hline$\lambda$ & Volume fraction & {$[-]$} \\
\hline$\rho$ & Density & {$\left[\mathrm{Kg} \cdot \mathrm{m}^{-3}\right]$} \\
\hline$\mu$ & Viscosity & Pa.s \\
\hline \multicolumn{3}{|c|}{ Subscripts } \\
\hline G & Gas & \\
\hline $\mathrm{i}$ & Inlet & \\
\hline $\mathrm{L}$ & Liquid & \\
\hline M & Mixture & \\
\hline $\max$ & Maximum & \\
\hline $\min$ & Minimum & \\
\hline $\mathrm{P}$ & Peak & \\
\hline $\mathrm{s}$ & Slug & \\
\hline$S$ & Superficial & \\
\hline $\mathrm{T}$ & Threeshold & \\
\hline
\end{tabular}




\section{Introduction}

Gas-liquid two-phase flows are encountered in various industrial applications including, without being exhaustive, crude-oil and gas production, crudes transportation, nuclear power plants, steam production and transport in power stations. The resulting flow regime would depend on the phasic flow rates, fluid properties, diameter and inclination of the pipe.

Among of the flow regimes which could be found in horizontal or near-horizontal pipes, intermittent flow is the most complex one to predict with annular flow. Indeed, this flow is characterized by an intermittency, in space and time, of both phases. For instance, a gas pocket flowing in a liquid layer succeeds a liquid slug which reaches the upper wall of the pipe (or blocks the whole section area). The intermittent flow, with constant phasic gas and liquid flow rates, could lead to large fluctuations of flow parameters such as local pressure, void fraction, mass flow rates of both phases and the velocity fields, in axial or radial directions (Kong et (2017)). These fluctuations may involve an amplification of the erosion-corrosion phenomenon (Villareal et al., 2006), the accelerating aging of pipes leading to an increase in equipement maintenance cost (Deendarlianto et al. (2016)), the destruction of industrial devices (Bagci (2004), Ahmed (2012), Wood et al (2013)) in addition to the generation of significant pressure losses, compared to other flow regimes.

Previous studies (Mandhane et al (1974), Vaze and Banerjee (2011, 2012), Kong and Kim (2017)) have divided the intermittent flow into two distinct regimes: plug and slug flows. The difference between the latters lies in the level of turbulence inside the slug body which is more important in slug flow compared to plug flow (Kesana et al. (2017)). For plug flow, the low level of turbulence results in the absence of gas bubbles into the liquid slug (Barnea et al. (1980)). Regardless to the similarities between the two regimes, it is necessary to precise that their dynamic characteristics, such as pressure drop, local void fraction, gas-bubble shape, length and shape of the liquid slug, as well as local flow velocity are different. These discrepancies are due to the presence, in the slug regime, of gas bubbles and the resulting hydrodynamics phenomena inside liquid slugs (bubble breakup, collapse, agglomeration, coalescence and collision) (Thaker and Banerjee (2016a))

Several authors have denoted that the slug flow can also be subdivided into several sub-regimes. Lin and Hanratty (1987b), in their investigation of the pseudo-slug regime, showed that this sub-regime of the slug flow is characterized by the presence of large waves, touching briefly the top of the pipe wall without blocking the entire pipe section area. A flow map, summarizing their work, was proposed for a $25.4 \mathrm{~mm}$ and $95.3 \mathrm{~mm}$ ID pipe. Hanratty (2013) described, in these maps, the lower boundary of the pseudo-slug region as the locations where large amplitudes waves were initiated. These waves could coalesce and touch the top of the pipe to form a possible slug. The higher boundary of this region was defined by the stability of a slug. Using the cross-correlation between two absolute pressure signals provided by two taps, Lin and Hanratty (1987a) suggested to distinguish between the pseudo-slug and slug flow. The pseudo-slugs should not be confused with the roll-waves. The roll waves, according to Hanratty (2013), are large-wavelength disturbances with steep fronts gradually sloping back.

In order to observe and compare pseudo-slug flow and churn flow regimes, Parsi et al. (2017) used a spacial-temporal data obtained with a Wire-Mesh Senor (WMS) on a $67.2 \mathrm{~mm}$ ID pipe in both horizontal and vertical configurations. They found that the pseudo-slugs is a continuous gas core surrounded by a large interfacial wave, or a core including a gas-liquid mixture. The same characteristic feature was observed on the huge wave encountred in the churn flow. Using 
the same experimental setup, Kesana et al. (2017) observed the simultaneous flow of liquid slugs, pseudo-slugs and high amplitude waves at low superficial gas velocity.

Rahmandika et al. (2018), using a high speed camera for studying the transition stratified/slug flow on a $26 \mathrm{~mm}$ ID pipe, observed for intermediate gas flow rates, the roll waves were developed continuously, coalesce to formroll-waves with higher amplitudes. Once these rollwaves touched the top of the pipe, the pseudo-slugs were formed. Hudaya et al. (2019) carried out an experimental investigation on different structures, including pseudo-slug flow and roll waves, that exist in transition regions between stratified and slug flows. They quantified the frequency, the velocity, the wave amplitude and the wave length of theses structures and proposed correlations to estimate theses parameters.

Bendiksen (1984) carried out series of experiments on the effect of tube inclination on elongated bubble motion with respect to tube diameter, liquid Reynolds and Froude numbers of the mixture $F r_{M}$ defined as $F r_{M}=V_{M} / \sqrt{g D}\left(V_{M}\right.$, g and D being respectively the mixture velocity, gravity and pipe diameter). The author pointed out, by studying the effect of $F_{M}$ on the translational velocity of a slug unity (slug body with gaz's pocket), a physical discontinuity occured at $F r_{m} \sim 3.5$ in a $24.2 \mathrm{~mm}$ ID pipe. This may be explained by the existence of a transition between two slug flow sub-regimes. Thereafter, Bertola (2002) and Thaker and Banerjee (2016b) observed the same discontinuity phenomenon.

Paglianti et al. (1996) examined void fraction, translational velocity as well as slug length evolution by time signals analysis obtained from capacitance probe and gamma densitometer, in case of a pipe of $31.7 \mathrm{~mm}$ ID pipe with air and oil as working fluids. A physical discontinuity for a Froude number of the mixture $F r_{M}$ close to 6-7,5 was recorded indicating a transition from elongated bubbles to slug flow. The difference between the critical Froude number values found by Paglianti et al (1996) and those obtained by Bendiksen (1984), Bertola (2002) and Thaker and Banerjee (2016b) can be explained by the nature of the fluids used. Indeed, the latters used water as a liquid.

An extensive theoretical investigation combined with liquid holdup measurements at various points in a horizontal $76.3 \mathrm{~mm}$ ID pipe were carried out by Woods and Hanratty (1999). The authors proposed a map to classify sub-regime of slug flow taking into account the distance from the inlet, where the slugs form, and the inlet Froude number $F r_{i}\left(F r_{i}=V_{M} / \sqrt{g H_{L \max }}\right)$, with $\mathrm{H}_{\text {Lmax }}$ being the liquid height. This map has three zones: in the first one, the slug forms at distance from inlet $L / D>40$ and for $F r_{i}<1$. In the second zone, the slugs form at a distance $L / D>40$ and for $F r_{i}>1$. In the third one, the slugs appear at a distance $L / D<40$. The slugs formed for each zone have a particular hydrodynamics.

Based on the slug liquid length, observed in a $52 \mathrm{~mm}$ ID pipe, Kadri et al (2009) divided the slug flow into three sub-regimes. A similarity is observed between their proposed map and that of Woods and Hanratty (1999). Moreover, the length of the liquid slug depends on the mechanism of the slugs formation.

By investigating the morphology of the gas-liquid interface and the aeration inside the liquid slug in a $25 \mathrm{~mm}$ ID pipe, Thaker and Banerjee (2015) split the slug flow into five sub-regimes:

- The first one, so-called onset of slug flow, is composed of a stratified regime with briefly appearance of few slugs. This sub-regime is a transition between the separate phase flow and the intermittent flow.

- The less aerated slug regime is characterized by liquid slugs containing few bubbles. 
- The slug and plug flow regimes are characterized by the alternated presence of liquid slug without bubbles and aerated liquid slug.

- The highly aerated slug flow which is characterized by slugs holding many bubbles.

- The slug and wavy zone regime is characterized by a wavy profile at the interface between the gas pocket and the liquid film.

Therefore, Thaker and Banerjee (2015), summarized their work by building a flow map that uses the physical parameters of the fluids as well as the inlet conditions as coordinates.

After studying the slug flow hydrodynamics, for either plug flowwhich includes the plug flow and plug and slug flows), less aerated slug flow and highly aerated slug flow (which include the highly aerated slug flow and the slug and wavy flow), Thaker and Banerjee (2016a) developed a flow map to undertake erosion and corrosion phenomena due to the intermittent nature of the flow. The proposed map is composed of eight zones, each zone is characterized by one or more erosion-corrosion mechanisms.

Dinaryanto et al. (2017) examined the mechanisms of the slug flow development from a series of visualizations and measurements of static pressure in a $26 \mathrm{~mm}$ ID pipe. Three slug mechanisms were then identified: i.e. coalescence, growth mechanism and large disturbance of waves. According to the mechanisms acting on the slug development, Dynaryanto et al. (2017) proposed a map to classify the slug flow containing five zones; Zone 1: pseudo slug and roll wave; zone II: wave growth (WG); zone III: disturbance wave and wave growth (DW+WG); Zone IV: disturbance wave and wave coalescence (DW+WC); Zone V: wave coalescence (WC). The map resulting displays a huge difference with that of Woods and Hanratty (1999).

Deendarlianto et al. (2019) carried out an experimental investigation on $16 \mathrm{~mm}, 26 \mathrm{~mm}$ and 50 $\mathrm{mm}$ ID pipe, in order to observe the hydrodynamic behavior of air-water two-phase flow near the transition to slug flow. The flow patterns observed (stratified smooth, stratified wavy, plug, slug and pseudo-slug) were used to develop a flow map for the three pipe diameters used. Similarities between the flow map obtained for $26 \mathrm{~mm}$ ID and the one of Lin and Hanratty (1987b) for $25.4 \mathrm{~mm}$ ID were observed. Similtiude between mechanism of slug initiation and the sub-regime was also found. Indeed, the wave growth mechanism (WG) is responsible for a transition from stratified smooth to plug or Less Aerated Slug flow (LAS). The wave coalescence (WC) induced the formation of Highly Aerated Slug flow (HAS) from stratified wavy or roll wave through pseudo-slug.

Despite decades of theoretical or experimental investigations an ultimate model that describes the intermittent flow phenomena in place is yet absent. This is due essentially to the complexity of the intermittent regimes, in regards of their variety and irregularity. The exact nature of the intermittent flows is not yet well known (Fabre and Liné, 1992). Thus, to predict the intrinsic parameters of such flows, experimental studies and developed correlations are required to close the models and validate the numerical results as well (Thaker and Banerjee, 2016b). Among these parameters, the slug frequency, defined as the number of slug liquid passing at a fixed position in the pipe per time interval, is of primary importance. According to Hill et al. (1996), the corrsion in pipes depend directly on the slug frequency. Due to the random nature of the initiation, evolution and dissipation along pipelines of the slug flow (Al-Safran (2012)), the frequency of slugs is considered as the most complicated parameter to quantify. Henceforth, a great effort has been devoted to the study the latter in recent years.

Numerous models for the slug frequency prediction can be found in the litterature, whether theoretical or semi-mechanistic (Taitel and Dukler (1977), Tronconi (1990) and Kadri (2014)) 
or empirical. The limits of theoretical models, due to the lack of physical knowledge on slug frequency phenomena, lead to use more empirical correlations. The main empirical correlations are summarized in Table 1 with the prevailing experimental conditions. A simple examination of correlations summarized in the table 1 shows that these correlations are quite different. Most of the empirical models were based on the methodology of Gregory and Scott (1969), who developed the first correlation for slug frequency estimation. In others words, there were based on experimental database generated at a laboratory scale on a small diameter pipe with air-water mixture. This correlations used superficial phasic velocities and pipe diameter as input parameters. Another approach is based on data collected from petroleum fields, this is the case for correlations of Hill and Wood (1990, 1994) and Shea et al. (2004). This kind of correlation uses a parameter (liquid holdup) which is not easy to estimate. Shea et al. (2004) estimated the influence of pipe's length (from the entry). Indeed, the liquid slugs coalesce and the slug frequency decreases along the pipe. Shea et al. (2004)proposed a first correlation which takes into account this parameter (pipe's entry length). Thaker and Banerjee (2015) by measuring the slug frequency, at $30 \mathrm{D}, 60 \mathrm{D}, 120 \mathrm{D}, 190 \mathrm{D}$ and $260 \mathrm{D}$ from the input, developed another correlation which took into account the pipe length. In recent years, many authors argued that the liquid viscosity has an influence on slug frequency, leading to the developpement of a number of correlations (Gokcal et al. (2009), Al-Safran (2009), Schulkes (2011), Okezue (2013), Zhao et al. (2013), Archibong (2015), Abulkadir et al. (2016), Baba et al. (2017), Archibong-Eso et al. (2017)). Abdulkadir et al. (2016) found that the slug frequency data obtained in a $67 \mathrm{~mm}$ ID pipe with a mixture of air and silicone oil, can be well correlated using a gas based Strouhal number $S t_{G}\left(S t_{G}=f_{S} D / V_{S G}\right)$ and liquid volume fraction $\lambda_{L}$ $\left(\lambda_{L}=V_{S L} / V_{S L}+V_{S G}\right)$. Such observation was already reported by Fossa et al. (2003) and Wang et al. (2007) who used air-water mixture. One should note that Fossa et al. (2003) used databased on a large range of pipe diameters $(19.05 \mathrm{~mm}-150 \mathrm{~mm})$.

The distinction between plug and slug flows was not made in several studies with a focus on the slug regime or gathered both regimes under the slug flow designation. Accordingly, the correlations cannot be directly applied to the plug regime, due to their distinct aeration characteristic. Based on such statement, Thaker and Banerjee (2016b) measured the slug frequency of plug and slug regimes in a $25 \mathrm{~mm}$ inner diameter horizontal pipe. After comparing their results with a correlations of Fossa et al. (2003) and Wang et al. (2007), the authors found that the correlations proposed by the above-mentionned authors correlate well the results for slug flow but underestimate those obtained for plug flow. Hence, they developed a new correlation for the prediction of the slug frequency relevant to both regimes.

Al-Safran (2012) explained that the slug frequency is randomless. The latter can be explained by the random and systematic errors inherent to experiments and field data sets on which the slug frequency correlations were based and by the different type of sub-regimes of slug flow

These observations can be confirmed when we see the low number of slug frequency studies performed taking into account the nature of sub-regimes (Woods and Hanratty (1999), Thaker and Banerjee (2015 and 2016a) and Dinaryanto et al. (2017)).

Such analysis of slug frequency correlations showed that each author develops a correlation according to the available databy taking Consequently, a great disparity between the predictions by different correlations exist and there is still no unanimous correlation valid for all conditions. Each correlation is relevant for experimental conditions in which it was developed.

Several experimental techniques, for slug frequency measurements, were developed. These were based on counting from a video recording (recently used by Thaker and Banerjee, 2016a,b) 
requiring then transparent pipes, on visualization and/or time signal processing of void fraction, liquid holdup or pressure. Techniques based on time signals can be classified into two categories: the counting method and spectral analysis.

The counting method, introduced by Hubbard (1965), consists on numbering traces on the time series left by the liquid slugs passage. The Spectral analysis method is based on the use of the Power Spectral Density (PSD) to extract the dominant frequency of the system. Using signals obtained from optical probe, Bertola and Cafaro $(2001,2002)$ compared results from counting method with those obtained by PSD. They found that for low phasic superficial velocities both methods give close results. Nonetheless, for high flow rates, the PSD gives two or three dominant frequencies. The authors concluded that slug flow may have several characteristic frequencies and characterizing it with a single frequency value does not reflect the flow dynamics of such flow. Therefore using PSD to characterize slug frequency is recommanded. Wilkens and Thomas (2008) introduced a new method for measuring slug frequency using differential pressure signal, this method relies on a threshold technique, already used for void fraction signal (Nydal (1991)) and for liquid holdup (Losi et al (2016)). The method was validated on a $52 \mathrm{~mm}$ pipe, using a video recording showing an average error of $5 \%$.

It is clear that there is no consensus to classify sub-regimes of intermittent flow and obviously a lack of experimental work focusing on slug frequency measurement for different sub-regimes. Therefore, the aim of this work is threefold: comparing measuring thechniques, generate data for subregime mapping purposes and predict slug frequency. For that purpose three techniques of slug frequency measurements were compared: from differential pressure signal, namely the counting method, the Wilkens and Thomas method as well as the Power Spectral Density (PSD). The experimental results generated were used to propose a new map for the sub-regimes classification. Finally, after comparing the obtained results for each sub-regime separately, with different existing correlations, a new correlation has been proposed for the prediction of the slug frequency, which takes into account the sub-regimes of the intermittent flow.

\section{Table 1.}

\section{Experimental facilities}

The experiments were carried out on a two-phase flow loop, given in Figure 1 (Arabi et al., 2018), designed specifically for the investigation of two-phase flows in a horizontal configuration, near atmospheric conditions with water/air as working fluids. This installation consists of a closed liquid circuit; with an open gas circuit and a pipe of $13 \mathrm{~m}$ long and $30 \mathrm{~mm}$ inner diameter. The pipe is made entirely of transparent acrylic resin (PMMA), to allow flow visualizations, fixed on a metal structure that has been designed to overcome the flow induced vibration phenomenon (FIV) (Miwa et al., 2015).

A type compressor (GIS,GS35/500/600 type, 5001 capacity and 8 bar maximum pressure) is used to generate the gas phase while water is pumped from a tank; using a type noryle pump OSBY M2C18.40,. Both fluids are mixed in a T-type mixer with a horizontal injection of the liquid phase and a vertical downward injection for the gas. After passing through the pipe, the two phases are separated within a separation tank. The air escapes from the top of the tank; while the water is pumped to the liquid tank by a second pump. 
The liquid flow rate was measured using the GE PT878 ultrasonic flowmeter, while the Krohn VA40 type rotameter (measuring range 1110- $9400 \mathrm{l} / \mathrm{h}$ ) measured the gas flow rate.

The flow patterns were observed and identified with a camera type Nikon D3400 with a maximum resolution of $6000 \times 4000$ pixels. The photography is positioned face to the pipe with about $1 \mathrm{~m}$ nearer. The images which were taken in burst mode, were aquired at axial distance of $173 \mathrm{D}$ from the input mixer. To optimize the image quality, a series of LED lamps were used as the light source. The position of photography,

An acquisition system composed of a Freescale MPX-2010 DP type differential pressure sensor (pressure range: -10 to $10 \mathrm{kPa}$ ), an amplification and filtering system, an acquisition card and a PC were used to obtain the differential pressure signal. The pressure differential choice, as instrumentation, was motivated by the fact that the pressure parameter (precisely the fluctuations of the pressure signal) has been used for a long time to characterize two-phase flows dynamics (Elperin and Klochko, 2002; Wang et al., 2003; Arabi et al., 2018) and estimating the void fraction (Wang et al., 2019). In addition, such type of instrumentation has proved its many advantages: easy to use, robust, reliable and usable in various conditions, inexpensive, practically non-intrusive and widely used in the industry (van Ommen et al., 2011). Such differential pressure sensor has the advantage, over the absolute pressure sensor, of filtering pressure fluctuations from outside the interval between two measuring points connected to the pressure sensor (Bai et al. 1997).

The sampling system was connected to the pressure taps located in the lower part of the pipe; following the methodology described by Gaspari et dos Reis (2007). The location of the pressure taps was put at a distance of 173.33 and 193.33 D far from the inlet mixer. These distances were choosen after some preliminary observations ensuring that the slug frequency is relatively constant at a distance of $150 \mathrm{D}$ far from the imput. Dinaryanto et al. (2017) who used a diameter pipe $(26 \mathrm{~mm})$ close to the one used in this study, found a relative stabilization of slug frequency at $100 \mathrm{D}$ from the entrance. For each pair of flow rates; a signal, with duration of 30s, was sampled with a frequency of $500 \mathrm{~Hz}$.

Table 2 summarizes the largest uncertainties in measuring the parameters used in our study. The accuracy on measuring flow rates, diameter and pressure drops were provided by the devices' manufacturers. The superficial velocities of each phase $\left(V_{S i}\right)$, which depend on the flow rate $(Q i)$ and pipe diameter $(D)$, was calculated according to:

$$
V_{S i}=\frac{4 Q_{i}}{\pi D^{2}}
$$

The uncertainties of phasic superficial velocities were estimated based on Moffat's method (1988). Indeed, the total uncertainty of $V_{S i}$ comprises the accuracy of all parameters used in its calculation. It is obtained by appropriately combining the standard uncertainties of these input parameters. The combined standard uncertainties of the estimate $V_{S i}$, denoted by function $U$ is calculated from the following equation :

$$
U\left(V_{S i}\right)= \pm \sqrt{\left(\frac{\delta f}{\delta Q_{i}} U\left(Q_{i}\right)\right)^{2}+\left(\frac{\delta f}{\delta D} U(D)\right)^{2}}
$$


Where $f$ is the function of $V_{S i}$ in term of input parameters, $U\left(Q_{i}\right)$ and $U(D)$ is a standard uncertainly of phasic flow rate and pipe diameter, respectively.

\section{Table 2.}

\section{Figure 1}

\section{Adopted methods for slug frequency quantification}

\subsection{Counting method}

The counting method, as implied by its name, is based on the peaks'counting (noted as $\mathrm{N}_{\mathrm{P}}$ ), defining the slug frequency $f_{\mathrm{s}}$ as follows:

$$
f_{s}=\frac{N_{P}}{T}
$$

Where $\mathrm{T}$ is the time signal duration expressed in seconds (s).

A pressure-drop signal example for a intermittent flow is provided in figure 2 . The signal is composed of various fluctuations where each peak can reveal the liquid slug passage (Weismann et al., 1979).

\section{Figure 2}

It should be observed that the passage of two-phase flow, especially in the intermittent flow case, may generate vibrations of the pipeline, as demonstrated by Zhong et al. (2007). It will lead to the appearance of some additional peaks within the signal which delivered by the differential pressure sensor. In some cases of the slug flow, roll waves or pseudo slugs can be found within the flow (Lin and Hanratty, 1987a and b; Rahmandhika et al., 2018; Deendarlianto et al., 2019). These waves (noted as sham liquid slugs) can generate some additional peaks into the signal. Thus, the counting method may overestimate the slug frequency value (Lin et al., 2013).

\subsection{Wilkens \& Thomas Method}

Wilkens and Thomas (2008) developed a new method which takes into account only peaks generated by the real liquid slugs since the pressure fluctuation amplitudes of the sham liquid slug are less than those of the real liquid slug. Such distinction between the peaks can be made based on the minimum pressure drop calculation (generated by the passage of a slug body between the pressure sensor terminals). The Wilkens and Thomas (2008) method relies on the following steps:

a) Calculation of the slug velocity is considered equal to the velocity of the gas-liquid mixing:

$$
V_{S}=V_{M}=V_{S L}+V_{S G}
$$


b) Calculation of the slug Reynolds number:

$$
R e_{s}=\frac{\rho_{s} D V_{S}}{\mu_{s}}=\frac{\rho_{L} D V_{S L}}{\mu_{L}}
$$

As $\rho_{\mathrm{s}}$ and $\mu_{\mathrm{s}}$ are the density and the slug viscosity, respectively, which are considered equal to the water density and its viscosity as well.

c) Calculation of the Fanning friction factor $\left(F_{f}\right)$ : for a smooth pipe and a Reynolds number in the range of 3000 to $3 \times 10^{6}$, Eq .6 gives an accurate estimation of $F_{f}$ according to Wilkens and Thomas (2008).

$$
F_{f}=0.0014+\frac{0.125}{R e_{S}^{0.32}}
$$

d) Estimation of the minimum stable slug length:

$$
L_{\text {min }} \geq D\left(10 V_{S L}+5\right)
$$

The latter is valid for $\mathrm{V}_{\mathrm{SL}}$ values between 0.1 and $2.0 \mathrm{~m} / \mathrm{s}$.

e) Calculation of the pressure drop required for one slug:

$$
\Delta P_{\text {oneslug }}=2 F_{f} \frac{L_{\min } \rho_{s} V_{s}^{2}}{D}
$$

It is worth noting, that if the minimum stable length (Eq. 7) is greater than the differential pressure tap spacing (i.e. 20D or $600 \mathrm{~mm}$ in our case), the use of the experimental differential pressure tap spacing as minimum stable length is required

f) Representation of the straight line of the pressure drop required for a slug on the differential pressure signal. This line serves as threshold.

g) Counting only the peaks that exceed the threshold.

h) Calculation of the slug frequency using the equation below:

$$
f_{S}=\frac{N_{P T}}{T}
$$

Where NPT is the number of peaks exceeding the threshold (Fig. 3).

\section{Figure 3}




\subsection{Power Spectral Density (PSD) method}

The Power Spectral Density (noted as PSD) is a mathematical operation that indicates the power distribution of a time series across the frequency spectrum. The latter is defined as the Fourier Transform of the autocorrelation of a temporal signal.

In signal processing, the Fast Fourier Transform algorithm (FFT) is generally used to obtain the Fourier Transform. The PSD is adapted to analyse the system's periodicity. As the widely used slug frequency being a periodicity which is approximated by the intermittence of slug flow (Lin et al. 2013), it makes sense to use the PSD for the characterization of the slug frequency. PSD was also used by Bertola (2003) to characterize the plug/slug flow transition. Figure 4 shows the frequencies spectrum obtained by using the PSD on the pressure drop signal provided in figure 2. The apparition of several peaks is noted. The emerging peak (i.e. the peak with the largest amplitude) represents the dominant frequency while the other peaks represent harmonics. The existence of harmonics revealed that the slug frequency is not a standard periodic function. In fact, the process for generating slugs is stochastic as demonstrated by Woods et al. (2006).

\section{Figure 4}

\section{Results and Discussion}

\subsection{Intermittent flow' sub-regimes identification}

90 acquisitions were made in the present investigation resulting of combination of phasic input flow rates. Liquid and gas superficial velocities were taken respectively between $0.436 \& 3.537$ $\mathrm{m} / \mathrm{s}$ and $0.145 \& 0.778 \mathrm{~m} / \mathrm{s}$.

First of all, a distinction between the sub-regimes of the intermittent flow was made. The approach, suggested by Thaker and Banerjee (2015), based on the visualization of the morphology of air-water interface and the presence of aeration inside the liquid slug, was adopted. The recognition and distinction between such sub-regimes was based on the analysis of photographies snaped.

Three intermittent flow sub-regimes were observed: Plug flow regime, less Aerated Slug (LAS) and Highly Aerated Slug (HAS).

- The plug flow regime, figure 5(a), is characterized by the absence of gas bubbles within the liquid slug (also called liquid plug). Meanwhile in some cases, the liquid plug can exhibit small amounts of air bubbles, which have detached at the tail of the gas bubble (Thaker and Banerjee, 2016a). The elongated bubble have an asymmetric round nose, and ends with a hydraulic jump of liquid phase; which does not reach the top of the pipe. A thin long tail is also found. Such sub-regime is encountered for low values of gas superficial velocity.

- The Less Aerated Slug (LAS), figure 5(b), is characterized by the presence of small and distinct numbers of bubbles within the liquid slug. The gas bubbles detach themselves from the gas bubble tail -reason to the increased shear stress at the interface between the bubble tail and the liquid slug nose- and flow to the upper part liquid slug until reaching 
the tail. This flow is also characterized by the gas bubbles with a bullet-shaped nose and blunt tails. This regime was observed for intermediate values of the gas flow rate.

- In the sub-regime Highly Aerated Slug (HAS), the flow is so fast that it was impossible to take a single slug body at the same time, therefore, figure 6 combines two captured images. Compared to the LAS (figure 5(b)), this flow was characterized by secondary eddies (i.e. swirl) as shown in fig. 5(c). Bubbles inside the liquid slugs were also observed. The bubbles size, within such chaotic (and strong) slugs, were smaller than those observed in the LAS flow. In addition, the number of bubbles grew untill becoming indistinguishable. Such regime was observed for high gas flow rate.

\section{Figure 5}

The results were compared with the transition lines of Thaker and Banerjee flow map (Thaker and Banerjee, 2015) as displayed in figure 6. This map uses phasic dimensionless superficial Reynolds numbers as coordinates system. These dimensionless numbers are given respectively for the gas phase $\left(\operatorname{Re}_{S G}\right)$ and liquid phase $\left(\operatorname{Re}_{S L}\right)$ as:

$$
\begin{aligned}
& R e_{S G}=\frac{\rho_{G} V_{S G} D}{\mu_{G}} \\
& R e_{S L}=\frac{\rho_{L} V_{S L} D}{\mu_{L}}
\end{aligned}
$$

where $\mathrm{D}$ is the pipe diameter, $\mathrm{V}_{\mathrm{SG}}$ and $\mathrm{V}_{\mathrm{SL}}$ are the gas and liquid superficial velocities, $\rho_{\mathrm{G}}$ and $\rho_{\mathrm{L}}$ are the gas and the liquid densities, respectively. The $\mu_{\mathrm{G}}$ and $\mu_{\mathrm{L}}$ are viscosities of gas and liquid, respectively.

One should note that a slight shift between our transition and those reported by Thaker and Banerjee (Thaker and Banerjee, 2015) is observed; due to the subjective nature of the adopted method for the distinction between the two sub-regimes and the conditions of each experiment.

\section{Figure 6}

The sub-regimes observations obtained were also compared with the transition lines of Dinaryanto et al. (2018) in figure 7. This map uses the superficial velocities of both phases as coordinates. It can be seen that the Dinaryanto et al. (2018) flow map predicts better the transition lines of the present study than the Thaker and Banerjee map.

Figure 7 


\subsection{Measuring slug frequency: comparison between three methods}

Figure 8 displays experimental data for the intermittent structures frequency obtained using three techniques (Wilikens and Thomas, Counting, PSD) as a function of the liquid superficial velocities. The results using the PSD and Wilkens \&Thomas were found to be close, in some cases, to a plug flow and less aerated slug flow. The impact of the superficial liquid velocity on the slug frequency was found to be very significant. Such impact was already reported by Thaker and Banerjee (2016b) for the case of the three sub-regimes studied. As expected, the counting method overestimates the results compared to the other methods.

\section{Figure 8}

To quantify such difference, the results obtained with the PSD method were compared with the Wilkens \&Thomas and the counting methods in Figures 9 and 10, respectively. Thereby, in the case of plug flow and less aerated slug flow, the Wilkens \& Thomas method slightly underestimated the results; compared to those given by the PSD. For the present data, the difference lies in the range of $-20 \%$ to $+60 \%$. Such disparity between results can be explained by the presence, confirmed by visual observations, of several liquid slugs within the space separating two pressure taps. Moreover,Wilkens \& Thomas method was developed (and validated) under the presence of a single liquid slug in the space between two pressure taps. Up to our knowledge, there was no work devoted to the validation of this method when several slugs existed simultaneously between two pressure taps. For the HAS case, the difference in frequency given by the threshold and the PSD methods becomes significant; compared to the others sub-regimes. For the HAS case, the difference between the two methods was found to be more significant ( up to $+700 \%$ ). This indicates the limit of the Wilkens \& Thomas method. Indeed, the calculated minimum pressure drop (using Eq. 3) is obtained by assuming that the slug body density is equal to the liquid phase density, neglecting thus the presence of gas bubbles in the slug body. These bubbles are very important in the HAS flow case (Fig 5c).

\section{Figure 9}

\section{Figure 10}

From Figure 10, as mentioned previously, the counting method overestimates the results compared to the spectral analysis (up to ten times the value). In fact the counting method does not differentiate between the peaks left by the passage of real and shame liquid slugs (see for instance section 3.2). Consequently, the PSD method seems to be the most worthwhile for slug frequency estimation for all the sub regimes.

\subsection{Comparison with literature data}

The slug frequency results obtained by PSD, for the various sub-regimes, and those given by Woods and Hanratty (1999), Thaker and Banerjee (2016a) and Dinaryanto et al. (2017) 
(summarized in Table 3) are plotted in Fig. 11 using the Gas Based Strouhal number $\left(S t_{G}\right)$ as a function of the Lockhart-Martinelli parameter $X$. The two parameters are defined in equations (12) and (13) respectively.

\section{Table 3}

$$
\begin{gathered}
S t_{G}=\frac{f_{S} D}{V_{S G}} \\
X=\sqrt{\frac{\left(\frac{d P}{d x}\right)_{L}}{\left(\frac{d P}{d x}\right)_{G}}}=\sqrt{\frac{\rho_{L}}{\rho_{G}}} \frac{V_{S L}}{V_{S G}}
\end{gathered}
$$

With $(d P / d x)_{L},(d P / d x)_{G}$ represent liquid and gas pressure gradients respectively.

\section{Figure 11}

It appeared that all data gave a linear fit with a positive slope. Hence, the slug frequency can be well correlated using the gas based Strouhal number, whatever the nature of sub-regime and the diameter of pipe. Such observation was already reported by Azzi et al. (2010) and Abulkadir et al. (2016).

In the same context, the present results as well as those of the literature (Table 3) are plotted in figure 12 using the gas based Strouhal number versus the mixture Froude number $\left(F r_{M}\right)$ which defined in equation 14. The choice of such dimensionless number was motivated by two factors. Firstly, the Froude number introduces the impact of the gravity, since the slug forms when air inertia (or growth of wave) is dominant over gravity. Secondly, such dimensionless number has been already used to represent the translational velocity of slug unit (Bendiksen, 1984; Bertola, 2002), the average void fraction in the liquid slug, the length of the slugs (Paglianti et al., 1996), the shape of gas pocket (de Oliveira et al., 2015) and the Slippage number (Abdelsalam et al., 2016).

$$
F r_{M}=\frac{V_{M}}{\sqrt{g D}}
$$

Our three sub-regimes data and those of Thaker and Banerjee (2016a), appeared to be located in the same areas unlike to the localization of their previous map (Thaker and Banerjee, 2015; see for instance Fig.6), in which a gap in the transition line is observed as mentioned previously. Such results confirm that this type of representation can be used as a flow map to predict the 
different sub-regimes of the intermittent flow. The dashed line represents the transition between the plug and the less aerated slug flow. The solid line represents the transition limit between the less aerated slug and the high aerated slug flow. Such transition line is occurred at a value of the mixture Froude number, $\mathrm{Fr}_{\mathrm{M}}$, of about 3.5 to 5, which is close enough to ones of Bendiksen (1984) and Thaker and Banerjee (2016b) which is equal to 3.5.

The transition line of our developed map reproduced the data of Thaker and Banerjee (2016 a or b?), whom classified the sub-regimes according to the morphology of the flow structures. Nevertheless, this map did not provide accurate results to be able to distinguish between the different zones, previously presented by Woods and Hanratty (1999) and Dinaryanto et al. (2017). Consequently, such map isn't valid for cases using the mechanism of formation classification of sub-regimes for the intermittent flow.

\section{Figure 12}

\subsection{Comparison with previous slug Frequencies' correlations}

The obtained slug frequency data for the three sub-regimes are compared separately with various empirical correlations (as summarized in table 1) (Gregory and Scott, 1969; Greskovitch and Shrier, 1972; Heywood and Richardson, 1979; Fetter, 1988; Nydal et al., 1992 ; Jepson and Taylor, 1993 ; Manolis et al., 1995 ; Zabaras, 2000 ; Fossa et al., 2003; Shea et al., 2004; Wang et al., 2007; Gokcal et al., 2009; Thaker and Banerjee, 2015; Thaker and Banerjee, 2016b; Al-Safran, 2016; and Baba et al., 2017) in figure 13. In the aim to quantify the disparity between each model predictions and the experimental data, the statistical approach previously developed by Govan (1988) was adopted. The latter is based on the computation of two statistical parameters such $\mathrm{F}$ and $\mathrm{S}$ (see for instance equations 15 and 16). Starting by the statistical parameter $\mathrm{F}$ which is a correction factor, in other words, the average factor by which the calculated value must be multiplied to give the experimental value; then the $\mathrm{S}$ statistical parameter which is a transformed standard deviation. Values of $F$ and $S$ of each case are summarized within Table. 4.

With :

$$
\begin{gathered}
F=\frac{1}{\exp (M)} \\
S=\exp (R)-1
\end{gathered}
$$

$$
\begin{gathered}
M=\frac{1}{n} \sum_{i=1}^{n} e(i) \\
e(i)=\log \left(\frac{f_{\text {smod }}(i)}{f_{\text {sexp }}(i)}\right) \\
R=\sqrt{\frac{1}{n} \sum_{i=1}^{n}(e(i)-M)^{2}}
\end{gathered}
$$

And $\mathrm{n}$ is the data number. 
Unlike the plug flow case, as shown by Figure 13 and referring to Table 4, the developed correlations of Fossa et al. (2003) and Wang et al. (2007) give good predictions in case of slug flows (both LAS and HAS). Such observation was previously confirmed by Thaker and Banerjee (2016b). The same observation is also valid for correlation of Gregory and Scott (1969), Greskovitch \& Shrier (1972), Heywood \& Richardson (1979) and Fetter (1988).

In addition, the correlation of Al-Safran (2016), with $F$ and $S$ values of about 1 and 0 , respectively, predicted well the present plug flow and HAS cases. When Wang et al. (2007) correlation is found better for the LAS regime prediction. However, correlations that have been developed using oil as a working fluid (i.e. Gokcal et al (2010) and Baba et al (2017)) underestimate significantly our experimental data.

Moreover, the calculated correction factor $\mathrm{F}$ given by each correlation is found different for each sub-regime; especially with the Jepson and Taylor (1993) one (see for instance Figure 13f). Such capital observation may prove that there is no ultimate correlation available and reliable for the three sub-regimes. Thus, it is seems important to search a unified correlation which takes into account the nature of such sub-regimes, which constitute the main objective of the next section.

\section{Figure 13}

\section{Table 4}

\subsection{Developed slug frequency' correlation}

The present study is concerned by the development of a unified correlation that predicts the slug frequency, taking into account the sub-regime nature. Thenceforth, from our experimental data, the gas based Strouhal number $\left(\mathrm{St}_{\mathrm{G}}\right)$, versus the liquid volume fraction $\left(\lambda_{L}\right)$ (eq. 20$)$, is displayed through figure 14.

Based on the primary presentation of Fossa et al. (2003) and Wang et al. (2007) (see for instance Eq. 19), an optimum fitting of our empirical data; for each sub-regime; is displayed throughout Figure 14, the computed coefficients A, B and C of eq. 21, are summarized in Table 5 .

$$
\begin{gathered}
\lambda_{L}=\frac{V_{S L}}{V_{M}}=\frac{V_{S L}}{V_{S L}+V_{S G}} \\
S t_{G}=\frac{A \lambda_{L}}{1+B \lambda_{L}+C \lambda_{L}^{2}}
\end{gathered}
$$


Afterwards, the developed correlation is plotted against the experimental data. As shown in figure 15, good agreement is observed with an maximum gap of about $\pm 25 \%$ for any subregime. A comparison between this figure with a predictions of different correlation (figure 13) show that our correlation was only model which predict all the data in this interval.

The computed statistical parameters for such developed correlation are given into Table. 6, for which the correction factor of each sub-regime is found to be around unity ( $F_{\text {Plug }}=0.997, F_{\text {LAS }}=$ $1.007, \mathrm{~F}_{\text {HAS }}=1.008$ ) when the transformed standard deviation in close to zero (SPlug $=0.089$, $\left.\mathrm{S}_{\mathrm{LAS}}=0.082, \mathrm{~S}_{\mathrm{HAS}}=0.085\right)$. Such noteworthy upshots obtained from the developped corellation exhibit better experimental prediction compared to correlations found in the literature (see Table.4).

Table 5

Figure 15

Table 6

Finally, the selected correlations and the correlation developed were compared with Thaker and Banerjee data (2016a). These data was not used in developement in our correlation. Parameters $\mathrm{F}$ and $\mathrm{S}$, to assess the predictions of each correlation, are summarized in Table 7. First of all, it can be seen that the predictions of correlations depend on the nature of the sub-regime. This is the same observation as that observed with our experimental results. It also appears from Table 7 that our correlation predicted the results of Thaker and Banerjee (2016a) well for slug flow with $F_{\text {LAS }}=0.999$ and $F_{\text {HAS }}=1.027$. For plug flow, the prediction of the developed correlation is correct $\left(\mathrm{F}_{\text {Plug }}=0.919\right.$ and $\left.\mathrm{S}_{\text {Plug }}=0.120\right)$ but it is below the predictions of the correlations of Fossa et al (2003) (FPlug $=0.942$ and $\left.S_{\text {Plug }}=0.060\right)$ and the correlation of Wang et al (2007) $\left(F_{\text {Plug }}=0.929\right.$ and $\left.S_{\text {Plug }}=0.088\right)$. However, these correlations predicted the data for LAS flows $\left(\mathrm{F}_{\text {LAS }}=0.932\right.$ and $\mathrm{F}_{\text {LAS }}=0.896$ respectively $)$ and HAS $\left(\mathrm{F}_{\mathrm{LAS}}=0.909\right.$ and $\mathrm{F}_{\text {LAS }}=0.865$ respectively) less well compared to the developed correlation. We can conclude that our correlation is the one that gives the best predictions of Thaker and Banerjee's data (2016a).

\section{Table 7}

\section{Conclusions}

The present work deals with the slug frequency of intermittent water / air flow in a horizontal pipe of $0.03 \mathrm{~m}$ ID. The study concerned the plug flow, the less aerated slug and the highly aerated slug. The measurements of the slug frequency were obtained using the differential 
pressure signal. After comparing the counting method, Wilkens and Thomas method and PSD, it has been found that the latter is the most suitable for measuring the slug frequency. A new map that uses the dimensionless numbers was proposed to classify the sub-regimes of intermittent flow based on the morphology of liquid slug. After comparing the experimental results with existing correlations, it was found that the correlations do not predict the outcome for the three sub-regimes in the same way. A new correlation, developed from the experimental data, which takes into account the nature of sub-regime was proposed. This correlation gave the best prediction for experimental data including Thaker and Banerjee (2016a) data which was not used in its developpement.

\section{Acknowledgments}

This work was partially funded by the project SONATRACH-U.S.T.H.B. (project number: SHU.S.T.H.B. RD N${ }^{\circ}$ ).

\section{References}

Abdelsalam, A., Cem, S., \& Eduardo, P. (2016). New dimensionless number for gas-liquid flow in pipes. International Journal of Multiphase Flow, 81, 15-19.

Abdulkadir, M., Hernandez-Perez, V., Lowndes, I. S., Azzopardi, B. J., \& Sam-Mbomah, E. (2016). Experimental study of the hydrodynamic behaviour of slug flow in a horizontal pipe. Chemical Engineering Science, 156, 147 161 .

Abdul-Majeed, G. H. (2000). Liquid slug holdup in horizontal and slightly inclined two-phase slug flow. Journal of Petroleum Science and Engineering, 27(1-2), 27-32.

Ahmed, W. H. (2012). Flow accelerated corrosion in nuclear power plants. In Nuclear Power-Practical Aspects. InTech.

Al-Safran, E. (2009). Investigation and prediction of slug frequency in gas/liquid horizontal pipe flow. Journal of Petroleum Science and Engineering, 69(1-2), 143-155.

Al-Safran, E. (2012, June). Probabilistic modeling of slug frequency in gas/liquid pipe flow using Poisson probability theory. In 8th North American Conference on Multiphase Technology. BHR Group.

Al-Safran, E. M. (2016). Probabilistic modeling of slug frequency in gas/liquid pipe flow using the Poisson probability theory. Journal of Petroleum Science and Engineering, 138, 88-96.

Arabi, A., Salhi, Y., Si-Ahmed, E. K., \& Legrand, J. (2018). Influence of a sudden expansion on slug flow characteristics in a horizontal two-phase flow: a pressure drop fluctuations analysis. Meccanica, 53(13), 33213338.

Archibong, A. (2015). Viscous multiphase flow characteristics in pipelines (Doctoral dissertation, PhD Thesis, Cranfield University, United Kingdom).

Archibong-Eso, A., Baba, Y., Aliyu, A., Zhao, Y., Yan, W., \& Yeung, H. (2017). On slug frequency in concurrent high viscosity liquid and gas flow. Journal of Petroleum Science and Engineering.

Azzi, A., Al-Attiyah, A., Qi, L., Cheema, W., \& Azzopardi, B. J. (2010). Gas-liquid two-phase flow division at a micro-T-junction. Chemical Engineering Science, 65(13), 3986-3993.

Baba, Y. D., Archibong, A. E., Aliyu, A. M., \& Ameen, A. I. (2017). Slug frequency in high viscosity oil-gas two-phase flow: Experiment and prediction. Flow Measurement and Instrumentation, 54, 109-123.

Bagci, S. (2004). An investigation of two-phase slug flow in inclined pipelines. Energy sources, 26(7), 627-638. Bai, D., Bi, H. T., \& Grace, J. R. (1997). Chaotic behavior of fluidized beds based on pressure and voidage fluctuations. AIChE Journal, 43(5), 1357-1361.

Barnea, D., Shoham, O., Taitel, Y., \& Dukler, A. E. (1980). Flow pattern transition for gas-liquid flow in horizontal and inclined pipes. Comparison of experimental data with theory. International Journal of Multiphase Flow, 6(3), 217-225.

Bendiksen, K. H. (1984). An experimental investigation of the motion of long bubbles in inclined tubes. International Journal of multiphase flow, 10(4), 467-483.

Bertola, V. (2002). Slug velocity profiles in horizontal gas-liquid flow. Experiments in Fluids, 32(6), 722-727. Bertola, V. (2003). Experimental characterization of gas-liquid intermittent subregimes by phase density function measurements. Experiments in Fluids, 34(1), 122-129.

Bertola, V., \& Cafaro, E. (2001). On the measurement of slug frequency in the horizontal gas-liquid flow. In 15 th AIAA Computational Fluid Dynamics Conference (p. 3035). 
Bertola, V., \& Cafaro, E. (2002). Slug frequency measurement techniques in horizontal gas-liquid flow. AIAA journal, 40(5), 1010-1012.

Cai, J. Y., Wang, H. W., Hong, T., \& Jepson, W. P. (1999, August). Slug frequency and length inclined large diameter multiphase pipeline. In Proc. of the Fourth International Symposium (pp. 195-202).

de Gaspari, C. A., \& dos Reis, E. (2007). On measuring dynamic pressure in multiphase flows $19^{\text {th }}$ International Congress of Mechanical Engineering November 5-9, 2007, Brasília, DF

de Oliveira, W. R., De Paula, I. B., Martins, F. J. W. A., Farias, P. S. C., \& Azevedo, L. F. A. (2015) Bubble

characterization in horizontal air-water intermittent flow. International Journal of Multiphase Flow, 69, 18-30.

Deendarlianto, Andrianto, M., Widyaparaga, A., \& Dinaryanto, O. (2016). CFD studies on the gas-liquid plug two-phase flow in a horizontal pipe. Journal of Petroleum Science and Engineering, 147, 779-787.

Deendarlianto, Rahmandhika, A., Widyatama, A., Dinaryanto, O., \& Widyaparaga, A. (2019). Experimental study on the hydrodynamic behavior of gas-liquid air-water two-phase flow near the transition to slug flow in horizontal pipes. International Journal of Heat and Mass Transfer, 130, 187-203.

Dinaryanto, O., Prayitno, Y. A. K., Majid, A. I., Hudaya, A. Z., Nusirwan, Y. A., \& Widyaparaga, A. (2017). Experimental investigation on the initiation and flow development of gas-liquid slug two-phase flow in a horizontal pipe. Experimental Thermal and Fluid Science, 81, 93-108.

Dinaryanto, O., Widyatama, A., Prestinawati, M., Indarto, \& Deendarlianto. (2018, August). The characteristics of the sub regime of slug flow in $16 \mathrm{~mm}$ horizontal pipe. In AIP Conference Proceedings (Vol. 2001, No. 1, p. 030008). AIP Publishing.

Elperin, T., \& Klochko, M. (2002). Flow regime identification in a two-phase flow using wavelet transform. Experiments in Fluids, 32(6), 674-682.

Fabre, J., \& Liné, A. (1992). Modeling of two-phase slug flow. Annual review of fluid mechanics, 24(1), 21-46. Fetter, C. P. (1988). Development of a clamp-on acoustic two-phase flow meter (Doctoral dissertation, M. Sc. thesis, TUDelft, Delft, The Netherlands).

Fossa, M., Guglielmini, G., \& Marchitto, A. (2003). Intermittent flow parameters from void fraction analysis. Flow Measurement and Instrumentation, 14(4-5), 161-168.

Gokcal, B., Al-Sarkhi, A., Sarica, C., \& Alsafran, E. M. (2009, January). Prediction of slug frequency for high viscosity oils in horizontal pipes. In SPE Annual Technical Conference and Exhibition. Society of Petroleum Engineers.

Govan, A. H. (1988). A note on statistical methods for comparing measured and calculated values. Atomic Energy Research Establishment, Thermal Hydraulics Division.

Gregory, G. A., \& Scott, D. S. (1969). Correlation of liquid slug velocity and frequency in horizontal cocurrent gas-liquid slug flow. AIChE Journal, 15(6), 933-935.

Greskovich, E. J., \& Shrier, A. L. (1971). Pressure drop and holdup in horizontal slug flow. AIChE Journal, 17(5), 1214-1219.

Greskovich, E. J., \& Shrier, A. L. (1972). Slug frequency in horizontal gas-liquid slug flow. Industrial \& Engineering Chemistry Process Design and Development, 11(2), 317-318

Hanratty, T. J. (2013). Physics of gas-liquid flows. Cambridge University Press.

Heywood, N. I., \& Richardson, J. F. (1979). Slug flow of air-water mixtures in a horizontal pipe: Determination of liquid holdup by $\gamma$-ray absorption. Chemical Engineering Science, 34(1), 17-30.

Hill, T. J., \& Wood, D. G. (1990, January). A new approach to the prediction of slug frequency. In SPE Annual Technical Conference and Exhibition. Society of Petroleum Engineers.

Hill, T. J., \& Wood, D. G. (1994, January). Slug flow: Occurrence, consequences, and prediction. In University of Tulsa Centennial Petroleum Engineering Symposium. Society of Petroleum Engineers.

Hill, T. J., Fairhurst, C. P., Nelson, C. J., Becerra, H., \& Bailey, R. S. (1996, January). Multiphase production through hilly terrain pipelines in Cusiana oilfield, Colombia. In SPE Annual Technical Conference and Exhibition. Society of Petroleum Engineers.

Hubbard, M. G. (1965). An analysis of horizontal gas-liquid slug flow (Doctoral dissertation, University of Houston).

Hudaya, A. Z., Widyatama, A., Dinaryanto, O., \& Juwana, W. E. (2019). The liquid wave characteristics during the transportation of air-water stratified co-current two-phase flow in a horizontal pipe. Experimental Thermal and Fluid Science, 103, 304-317.

Jepson, W. P., \& Taylor, R. E. (1993). Slug flow and its transitions in large-diameter horizontal pipes. International Journal of Multiphase Flow, 19(3), 411-420.

Kadri, U. (2014). A probabilistic approach for predicting average slug frequency in horizontal gas/liquid pipe flow. Oil \& Gas Science and Technology-Revue d'IFP Energies nouvelles, 69(2), 331-339.

Kadri, U., Zoeteweij, M. L., Mudde, R. F., \& Oliemans, R. V. A. (2009). A growth model for dynamic slugs in gas-liquid horizontal pipes. International Journal of Multiphase Flow, 35(5), 439-449. 
Kesana, N. R., Parsi, M., Vieira, R. E., Azzopardi, B., Schleicher, E., McLaury, B. S., ... \& Hampel, U. (2017). Visualization of gas-liquid multiphase pseudo-slug flow using Wire-Mesh Sensor. Journal of Natural Gas Science and Engineering, 46, 477-490.

Kong, R., \& Kim, S. (2017). Characterization of horizontal air-water two-phase flow. Nuclear Engineering and Design, 312, 266-276.

Kong, R., Kim, S., Bajorek, S., Tien, K., \& Hoxie, C. (2017). Experimental investigation of horizontal air-water bubbly-to-plug and bubbly-to-slug transition flows in a $3.81 \mathrm{~cm}$ ID pipe. International Journal of Multiphase Flow, 94, 137-155.

Lin, M., Liu, Y., Hu, Y., \& Che, D. (2013, July). Influence of the gas and liquid superficial velocity on slug frequency. In AIP Conference Proceedings (Vol. 1547, No. 1, pp. 253-263). AIP

Lin, P. Y., \& Hanratty, T. J. (1987a). Effect of pipe diameter on flow patterns for air-water flow in horizontal pipes. International Journal of Multiphase Fflow, 13(4), 549-563.

Lin, P. Y., \& Hanratty, T. J. (1987b). Detection of slug flow from pressure measurements. International Journal of Multiphase Flow, 13(1), 13-21

Losi, G., Arnone, D., Correra, S., \& Poesio, P. (2016). Modelling and statistical analysis of high viscosity oil/air slug flow characteristics in a small diameter horizontal pipe. Chemical Engineering Science, 148, 190-202.

Mandhane, J. M., Gregory, G. A., \& Aziz, K. (1974). A flow pattern map for gas-liquid flow in horizontal pipes. International Journal of Multiphase Flow, 1(4), 537-553.

Manolis, I. G., Mendes-Tatsis, M. A., \& Hewitt, G. F. (1995). The effect of pressure on slug frequency in twophase horizontal flow. In Multiphase Flow 1995 (pp. 347-354).

Miwa, S., Mori, M., \& Hibiki, T. (2015). Two-phase flow induced vibration in piping systems. Progress in Nuclear Energy, 78, 270-284.

Moffat, R. J. (1988). Describing the uncertainties in experimental results. Experimental Thermal and Fluid Science, 1(1), 3-17.

Nydal, O. J. (1991). An Experimental Investigation on Slug Flow(Doctoral dissertation).

Nydal, O. J., Pintus, S., \& Andreussi, P. (1992). Statistical characterization of slug flow in horizontal pipes. International Journal of Multiphase Flow, 18(3), 439-453.

Okezue, C. N. (2013). Application of the gamma radiation method in analysing the effect of liquid viscosity and flow variables on slug frequency in high viscosity oil-gas horizontal flow. WIT Transactions on Engineering Sciences, 79, 447-461.

Paglianti, A., Giona, M., \& Soldati, A. (1996). Characterization of subregimes in two-phase slug flow. International Journal of Multiphase Jlow, 22(4), 783-796

Parsi, M., Azzopardi, B. J., Al-Sarkhi, A., Kesana, N. R., Vieira, R. E., Torres, C. F., ... \& Hampel, U. (2017). Do huge waves exist in horizontal gas-liquid pipe flow?. International Journal of Multiphase Flow, 96, 1-23.

Rahmandhika, A., Dinaryanto, O., Widyatama, A., Hudaya, A. Z., Indarto, \& Deendarlianto. (2018, August). Visualization study in the transition flow pattern of stratified to slug flow of air-water two phase flow in a horizontal pipe. In AIP Conference Proceedings (Vol. 2001, No. 1, p. 030003). AIP Publishing.

Schulkes, R. (2011, June). Slug frequencies revisited. In 15th International Conference on Multiphase Production Technology. BHR Group.

Shea, R. H., Eidsmoen, H., Nordsveen, M., Rasmussen, J., Xu, Z., \& Nossen, J. (2004, June). Slug frequency prediction method comparison. In Proceedings of the 4th North American Conference on Multiphase Technology (pp. 227-237).

Silva, F. S., Toledo, V. M., Quinto, D. P., \& Maya, J. C. (1997). Experimental slug flow characterization in a horizontal pipe. Experimental Heat Transfer, Fluid Mechanics and Thermodynamics, 893-900.

Taitel, Y., \& Dukler, A. E. (1977). A model for slug frequency during gas-liquid flow in horizontal and near horizontal pipes. International Journal of Multiphase Flow, 3(6), 585-596.

Thaker, J., \& Banerjee, J. (2015). Characterization of two-phase slug flow sub-regimes using flow visualization. Journal of Petroleum Science and Engineering, 135, 561-576.

Thaker, J., \& Banerjee, J. (2016a). Influence of intermittent flow sub-patterns on erosion-corrosion in horizontal pipe. Journal of Petroleum Science and Engineering, 145, 298-320.

Thaker, J., \& Banerjee, J. (2016b). On intermittent flow characteristics of gas-liquid two-phase flow. Nuclear Engineering and Design, 310, 363-377.

Tronconi, E. (1990). Prediction of slug frequency in horizontal two-phase slug flow. AIChE Journal, 36(5), 701709.

van Ommen, J. R., Sasic, S., Van der Schaaf, J., Gheorghiu, S., Johnsson, F., \& Coppens, M. O. (2011). Timeseries analysis of pressure fluctuations in gas-solid fluidized beds-A review. International Journal of Multiphase Flow, 37(5), 403-428.

Vaze, M. J., \& Banerjee, J. (2011). Experimental visualization of two-phase flow patterns and transition from stratified to slug flow. Proceedings of the Institution of Mechanical Engineers, Part C: Journal of Mechanical Engineering Science, 225(2), 382-389. 
Vaze, M. J., \& Banerjee, J. (2012). Prediction of liquid height for onset of slug flow. The Canadian Journal of Chemical Engineering, 90(5), 1295-1303.

Vicencio, F. E., Schneider, F. A., Cozin, C., Barbuto, F. A., Da Silva, M. J., \& Morales, R. E. (2015, November). An Experimental Characterization of Horizontal Gas-Liquid Slug Flow. In ASME 2015 International Mechanical Engineering Congress and Exposition (pp. V07BT09A020-V07BT09A020). American Society of Mechanical Engineers.

Villarreal, J., Laverde, D., \& Fuentes, C. (2006). Carbon-steel corrosion in multiphase slug flow and CO2. Corrosion Science, 48(9), 2363-2379.

Wang, S. F., Mosdorf, R., \& Shoji, M. (2003). Nonlinear analysis on fluctuation feature of two-phase flow through a T-junction. International Journal of Heat and Mass Transfer, 46(9), 1519-1528.

Wang, W., Liang, X., Zhang, M., \& Sefiane, K. (2019). A new method for voidage correlation of gas-liquid mixture based on differential pressure fluctuation. Chemical Engineering Science, 193, 15-26.

Wang, X., Guo, L., \& Zhang, X. (2007). An experimental study of the statistical parameters of gas-liquid twophase slug flow in horizontal pipeline. International Journal of Heat and Mass Transfer, 50(11-12), 2439-2443. Weisman, J., Duncan, D., Gibson, J., \& Crawford, T. (1979). Effects of fluid properties and pipe diameter on two-phase flow patterns in horizontal lines. International Journal of Multiphase Flow, 5(6), 437-462.

Wilkens, R. J., \& Thomas, D. K. (2008). A simple technique for determining slug frequency using differential pressure. Journal of Energy Resources Technology, 130(1), 014501.

Wood, M. H., Arellano, A. V., \& Van Wijk, L. (2013). Corrosion Related Accidents in Petroleum Refineries. European Commission Joint Research Centre, report no. EUR, 26331.

Woods, B. D., \& Hanratty, T. J. (1999). Influence of Froude number on physical processes determining frequency of slugging in horizontal gas-liquid flows. International Journal of Multiphase Jlow, 25(6-7), 1195-1223.

Woods, B. D., Fan, Z., \& Hanratty, T. J. (2006). Frequency and development of slugs in a horizontal pipe at large liquid flows. International Journal of Multiphase Flow, 32(8), 902-925.

Wren, E., Baker, G., Azzopardi, B. J., \& Jones, R. (2005). Slug flow in small diameter pipes and T-junctions. Experimental Thermal and Fluid Science, 29(8), 893-899.

Zabaras, G. J. (2000). Prediction of slug frequency for gas/liquid flows. SPE journal, 5(03), 252-258.

Zhao, Y., Yeung, H., \& Lao, L. (2013, June). Slug frequency in high viscosity liquid and gas flow in horizontal pipes. In 16th International Conference on Multiphase Production Technology. BHR Group.

Zhong, X., Wu, Y., Li, D., Li, Z., \& Li, Q. (2007, June). Effect of Slug Flow on Pipe Vibration in Horizontal Pipeline. In AIP Conference Proceedings (Vol. 914, No. 1, pp. 537-541). AIP. 


\section{Tables captions}

Table. 1. A summary of empirical correlations for the slug frequency

Table 2. Uncertainly of measured parameters

Table 3: Experimental data bank.

Table 4: comparison between experimental data and selected correltions

Table 5: Empirical coefficients

Table 6: Comparison between experimental data with a developed correlation

Table 7: Comparison between data of Thaker and Banerjee (2016a) with the developed correlation 


\section{Figures captions}

Figure 1 Schematic of the experimental set up

(1): compressor; (2): gas flowmeters; (3): two-phase flow mixer; (4): measuring pipe; (5):

differential pressure transducer, (6): decantation tank; (7): air outlet; (8): pump; (9): liquid tank, (10): pump; (11): ultrasonic flowmeter

Figure 2 Pressure drop signal of slug flow $\left(V_{S L}=0.637 \mathrm{~m} / \mathrm{s}\right.$ and $\left.V_{S G}=1.572 \mathrm{~m} / \mathrm{s}\right)$

Figure 3 Signal of the pressure drop $\left(V_{S L}=0.637 \mathrm{~m} / \mathrm{s}\right.$ and $\left.V_{S G}=1.572 \mathrm{~m} / \mathrm{s}\right)$ : the threshold value was calculated by the method of Wilkens \& Thomas (2008)

Figure 4 Exemple of PSD obtained $\left(V_{S L}=0.637 \mathrm{~m} / \mathrm{s}\right.$ and $V_{S G}=1.572 \mathrm{~m} / \mathrm{s}$ )

(a) Plug flow $\left(\mathrm{V}_{\mathrm{SL}}=0.424 \mathrm{~m} / \mathrm{s}\right.$ et $\left.\mathrm{V}_{\mathrm{SG}}=0.436 \mathrm{~m} / \mathrm{s}\right)$

(b) Less Aerated Slug flow (LAS) $\left(\mathrm{V}_{\mathrm{SL}}=0.424 \mathrm{~m} / \mathrm{s}\right.$ et $\left.\mathrm{V}_{\mathrm{SG}}=1.572 \mathrm{~m} / \mathrm{s}\right)$

(c) Highly Aerated Slug flow (HAS) $\left(\mathrm{V}_{\mathrm{SL}}=0.424 \mathrm{~m} / \mathrm{s}\right.$ et $\left.\mathrm{V}_{\mathrm{SG}}=3.144 \mathrm{~m} / \mathrm{s}\right)$

Figure 5 Photography of different sub-regime of intermittent flow observed in the present study. Flow direction : from left to right.

Figure 6. Comparison between experimental data and Thaker and Banerjee (2015) flow map.

Figure 7. Comparison between experimental data and Dinaryanto et al. (2018) flow map.

Figure 8. Slug frequencies obtained by the three methods

Figure 9. Slug frequencies obtained from the Wilkens and Thomas method and the Power Spectral Density.

Figure 10. Slug frequencies obtained from the counting method and the Power Spectral Density.

Figure 11. Gas based Strouhal number against Lockhart-Martinelli parameter

Figure 12 Gas based Strouhal number against Froude number of mixture

Figure 13. Comparison between predictions of a selection of correlations and measuring slug frequency

Figure 14. Gas based Strouhal number vs liquid volume fraction

Figure 15. Comparison between prediction of proposed correlation and measuring slug frequency 


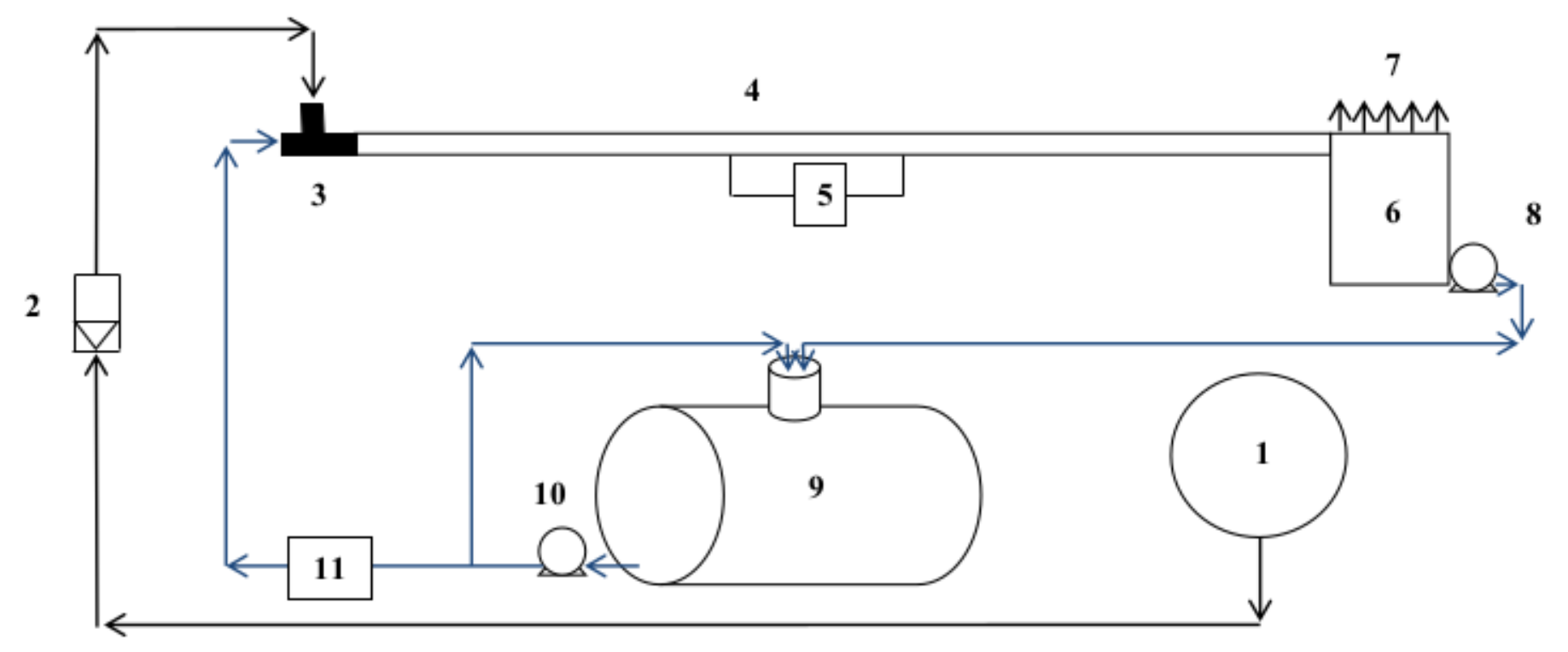




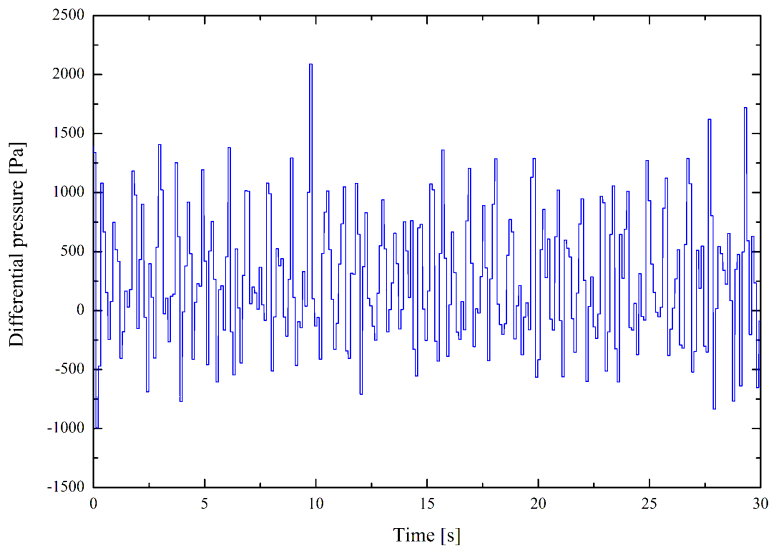




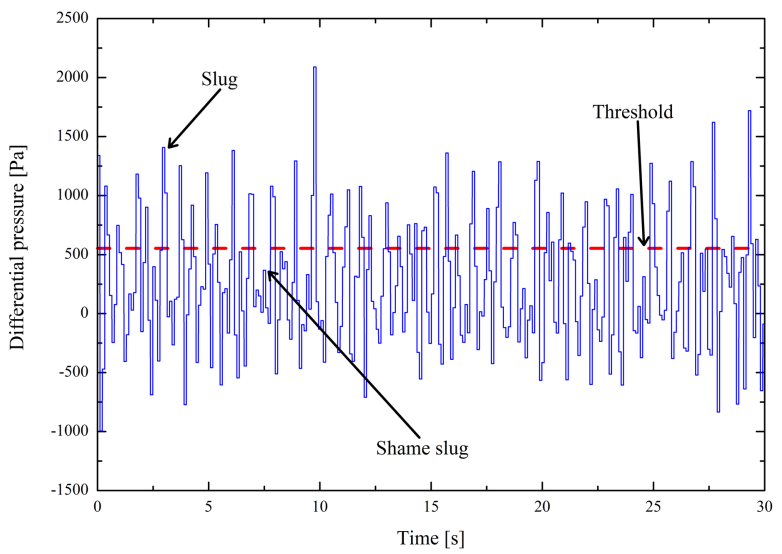




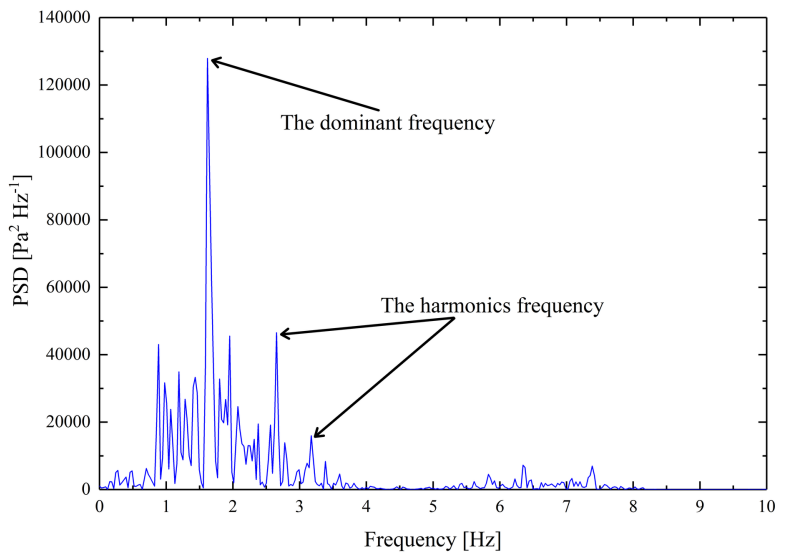





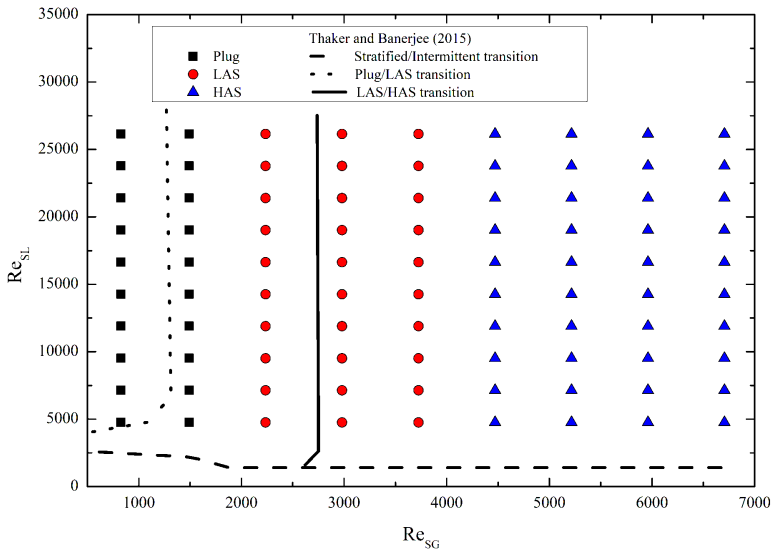




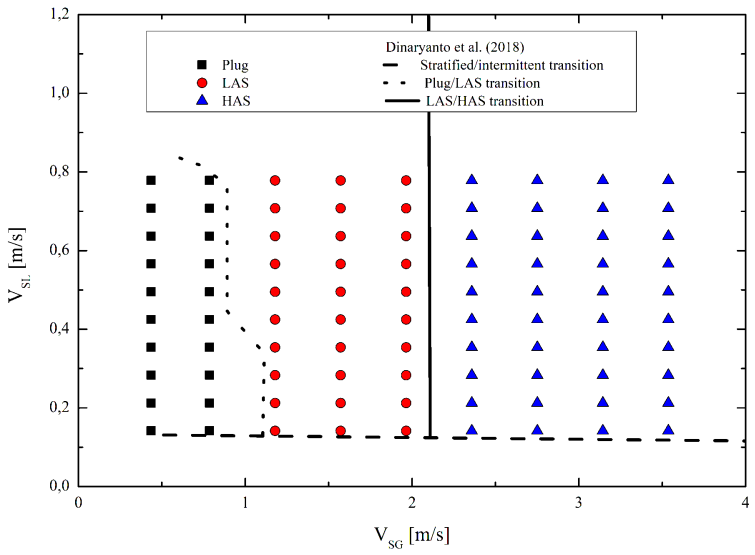




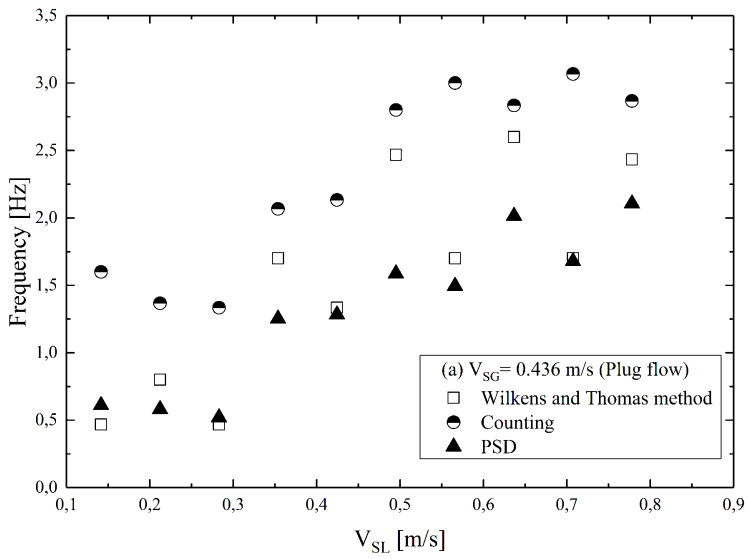




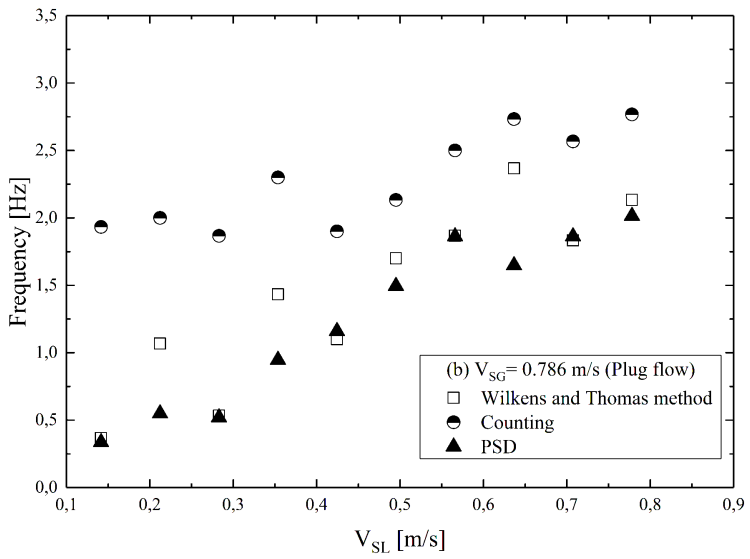




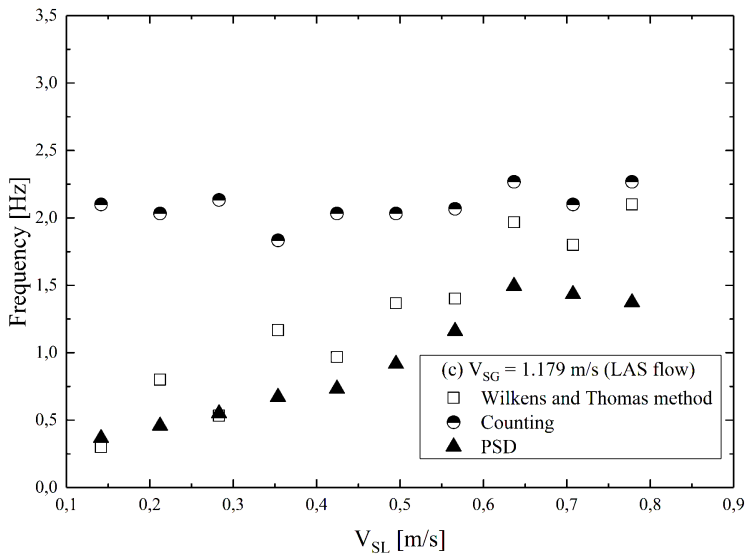




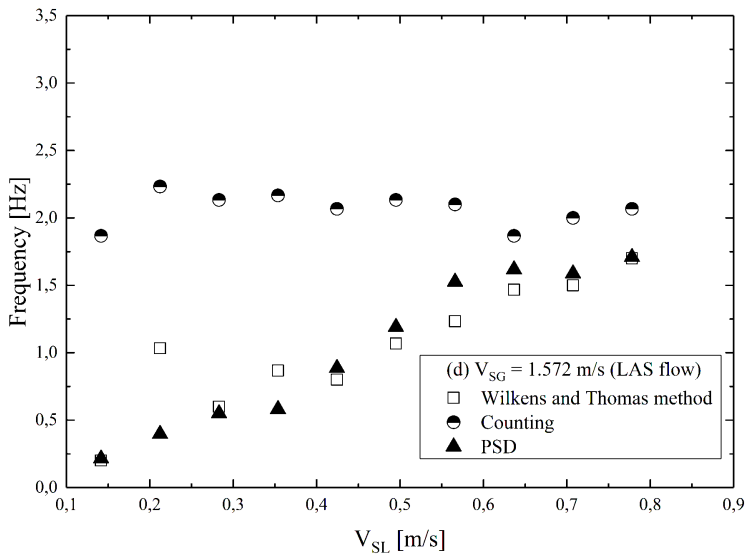




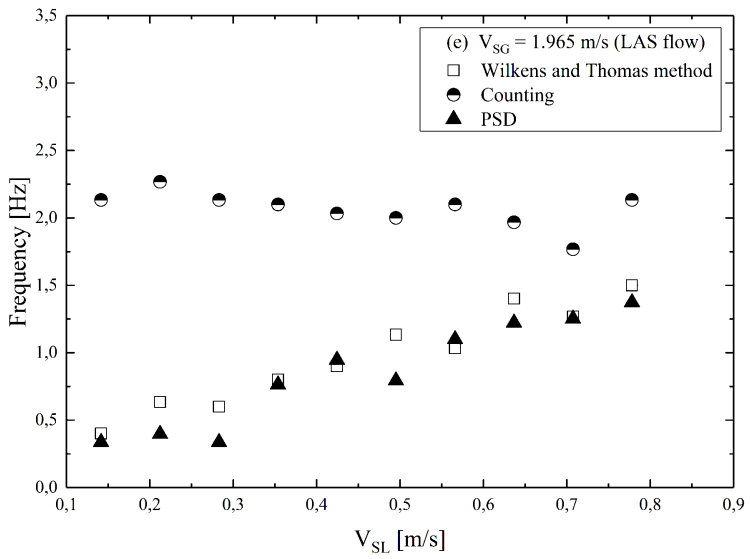




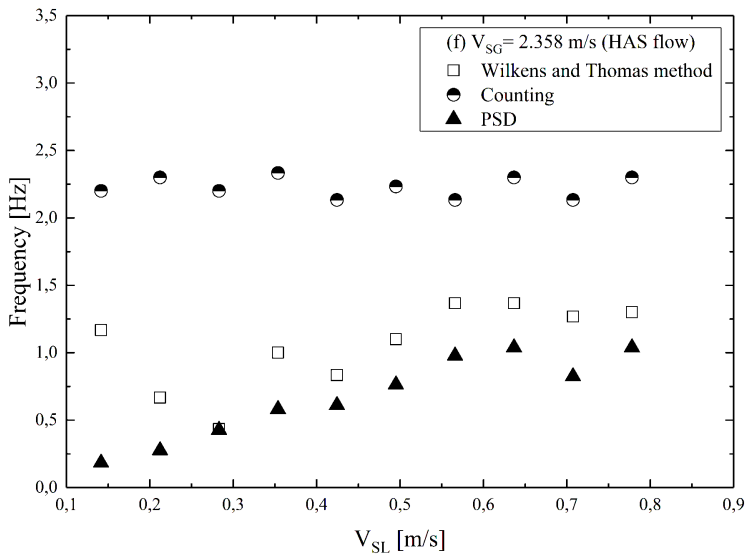




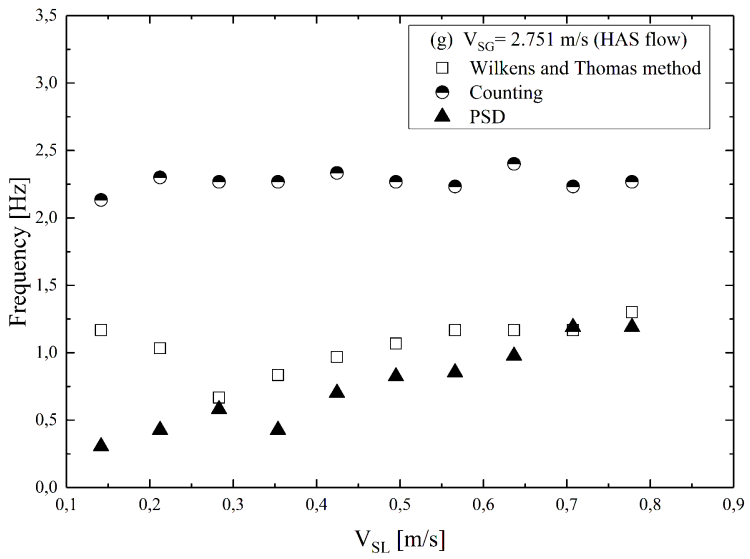




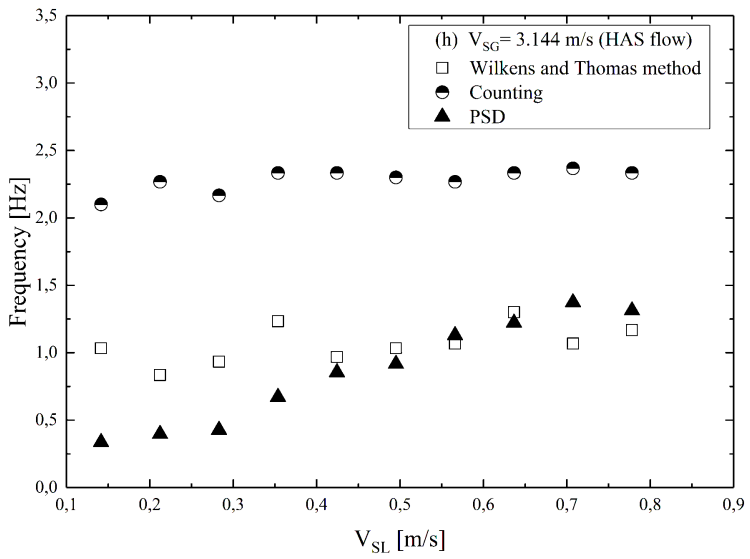




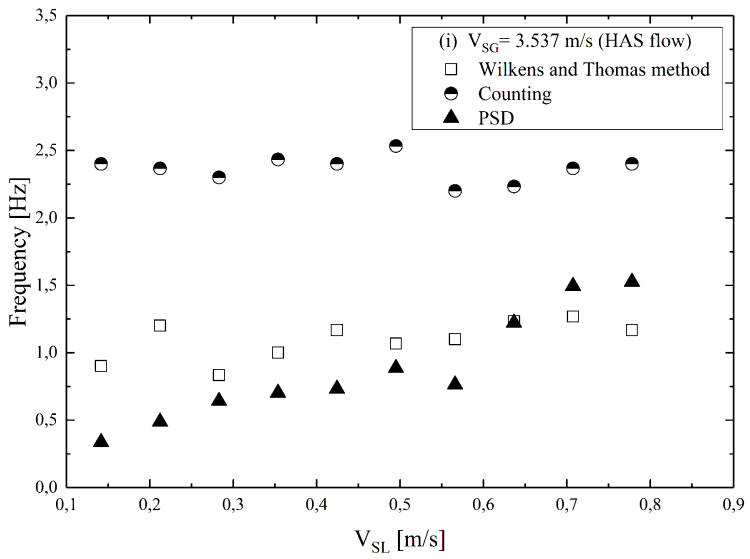




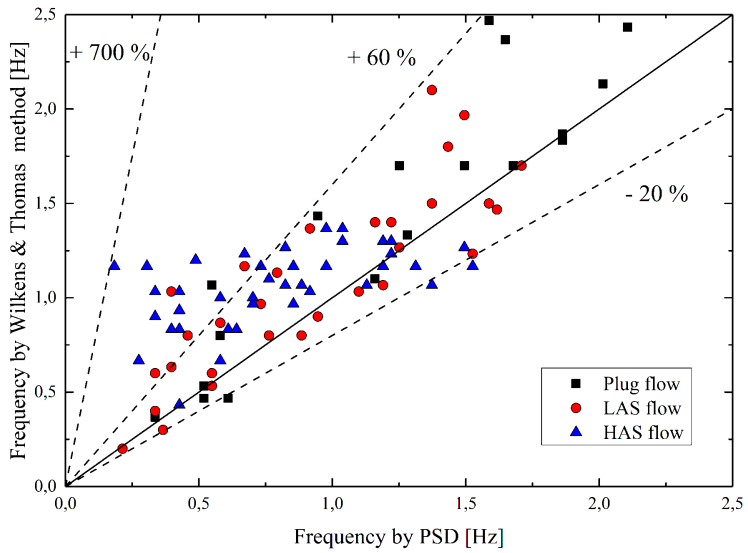




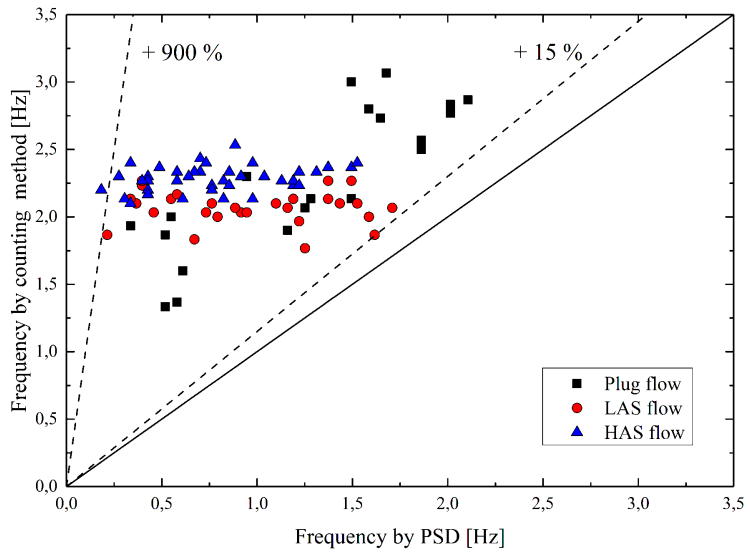




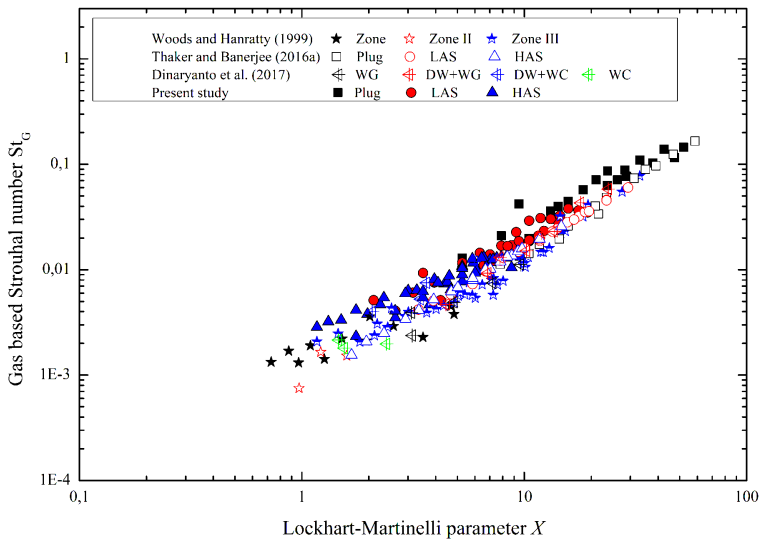




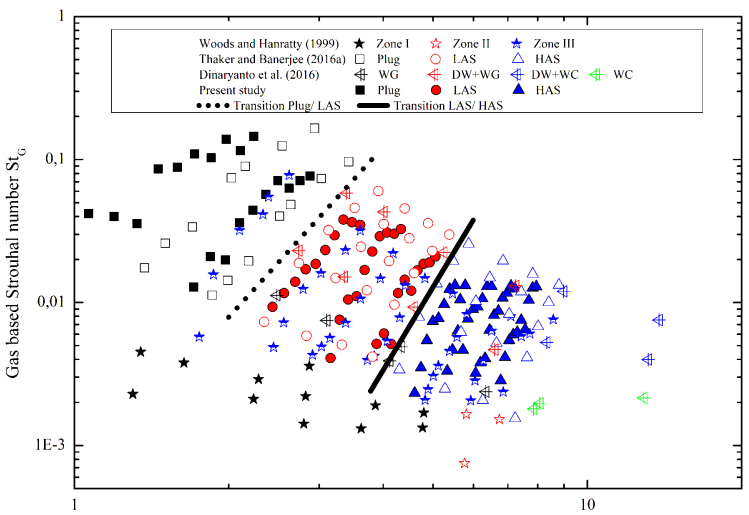

Froude number of mixture $\mathrm{Fr}_{\mathrm{M}}$ 


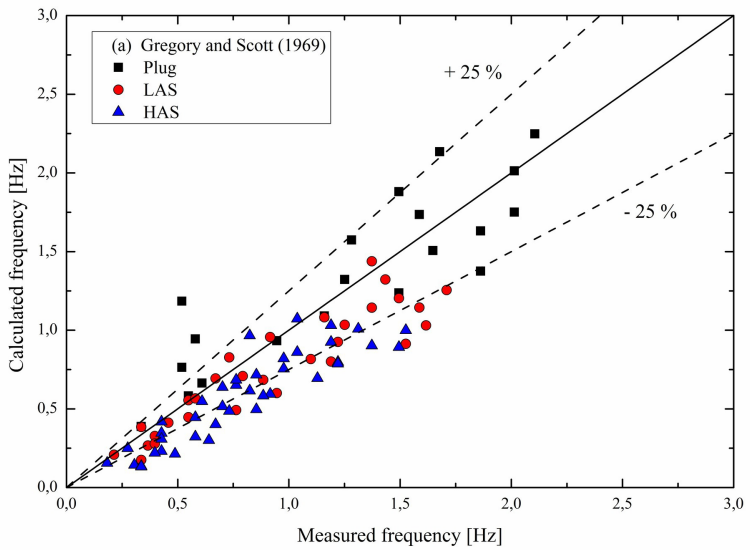




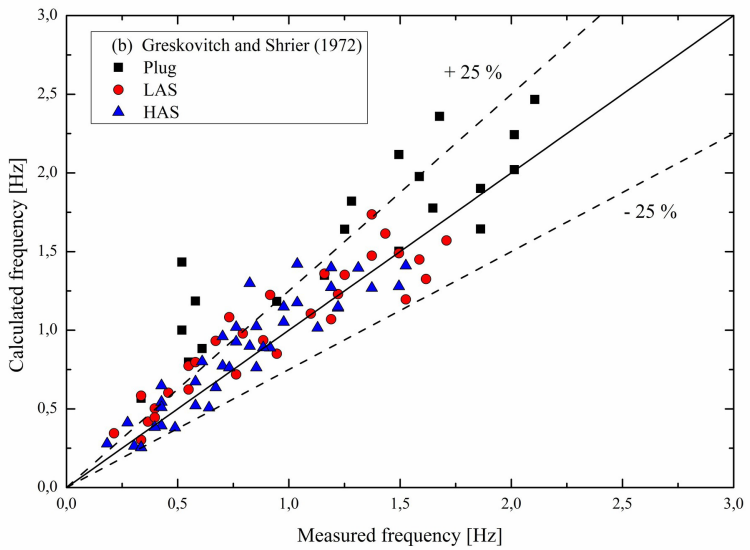




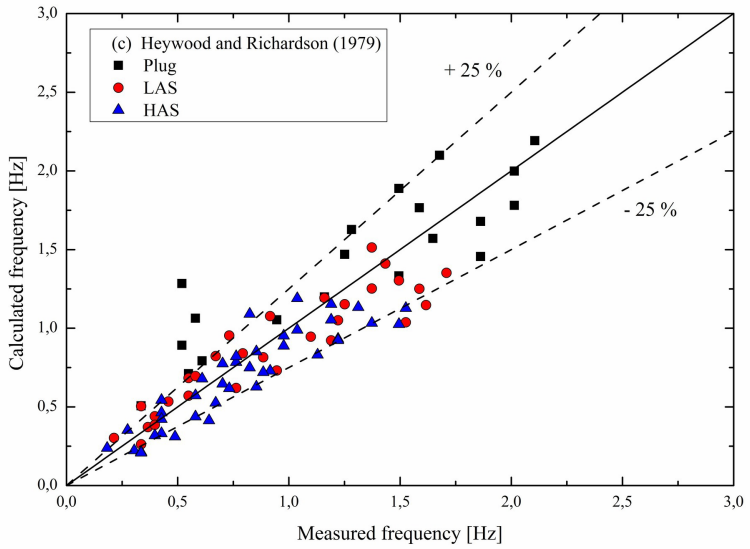




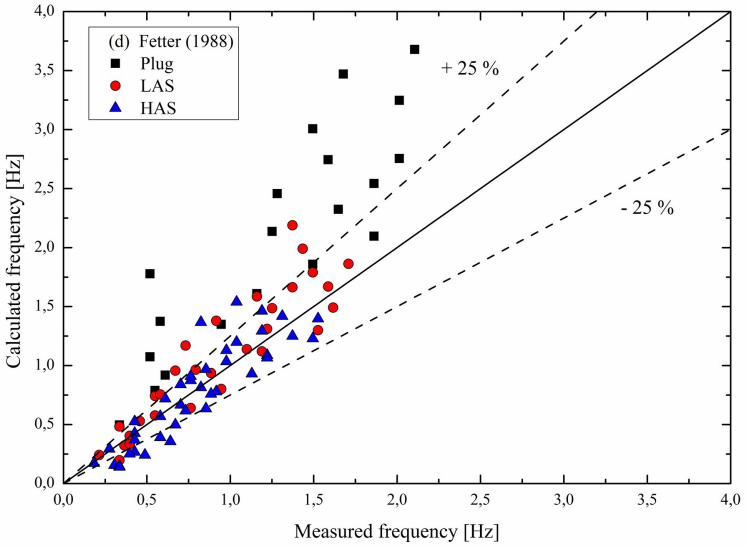




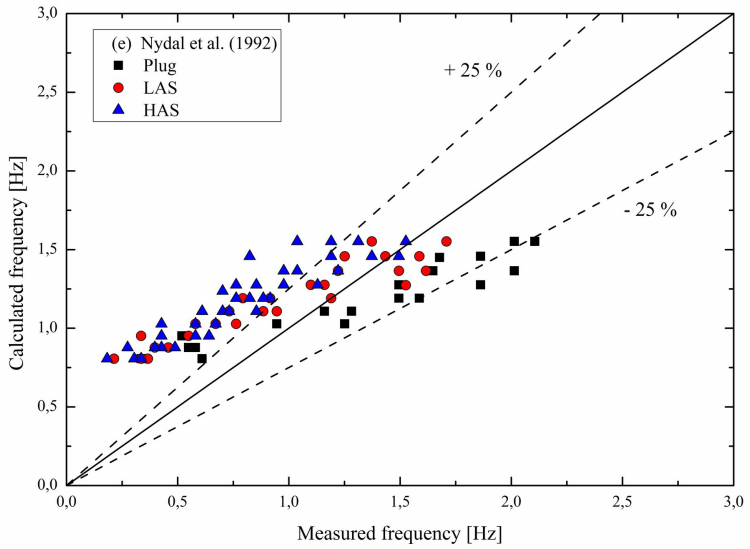




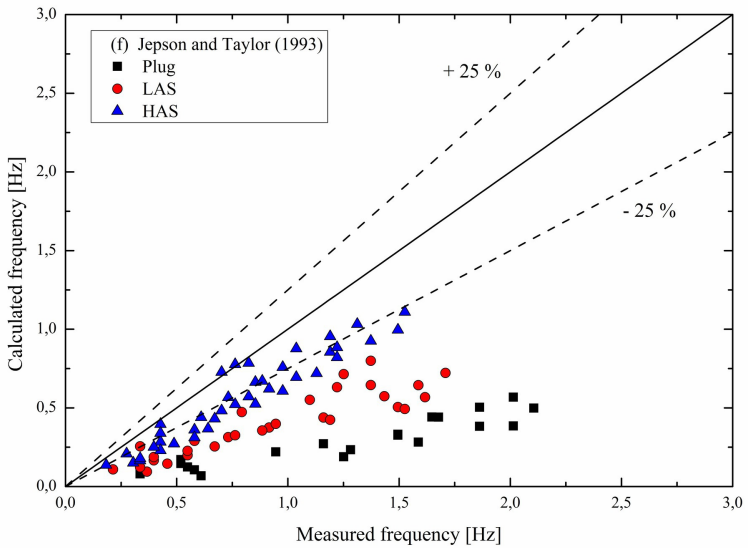




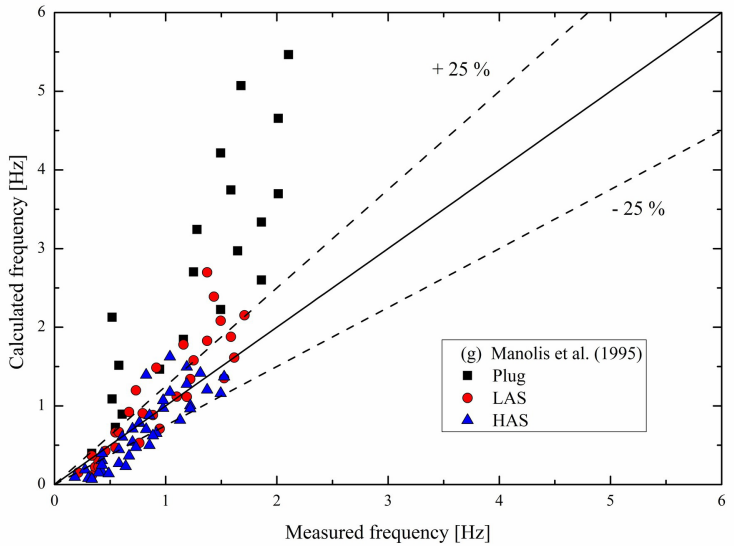




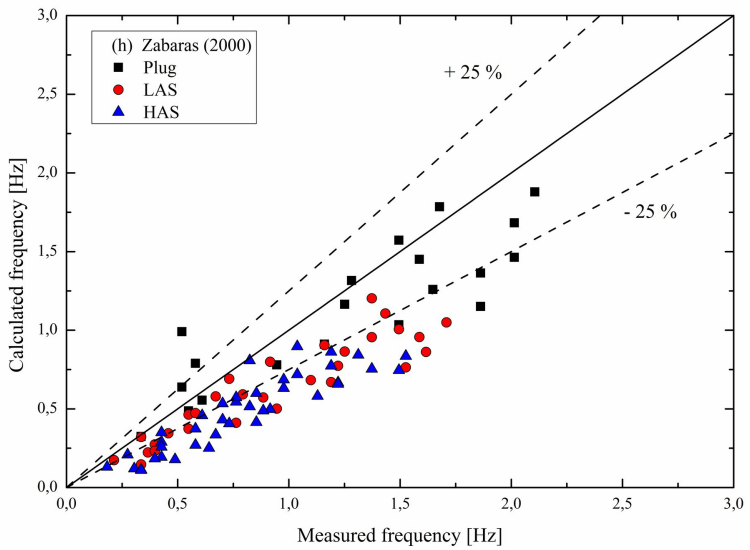




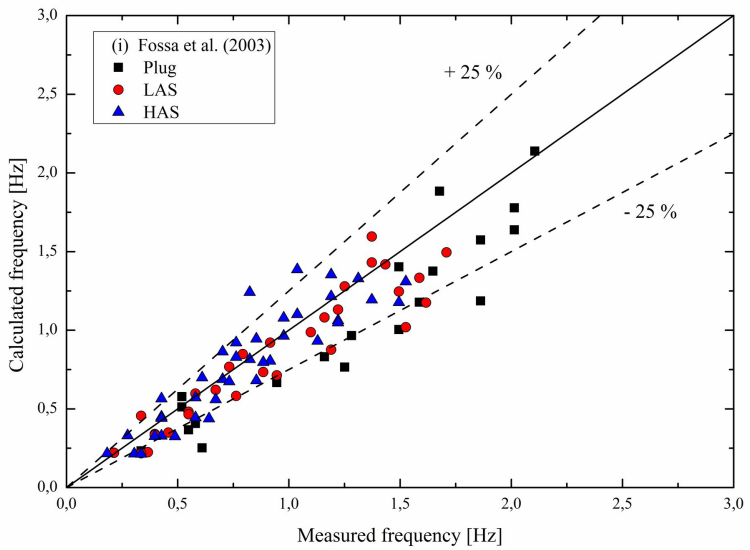




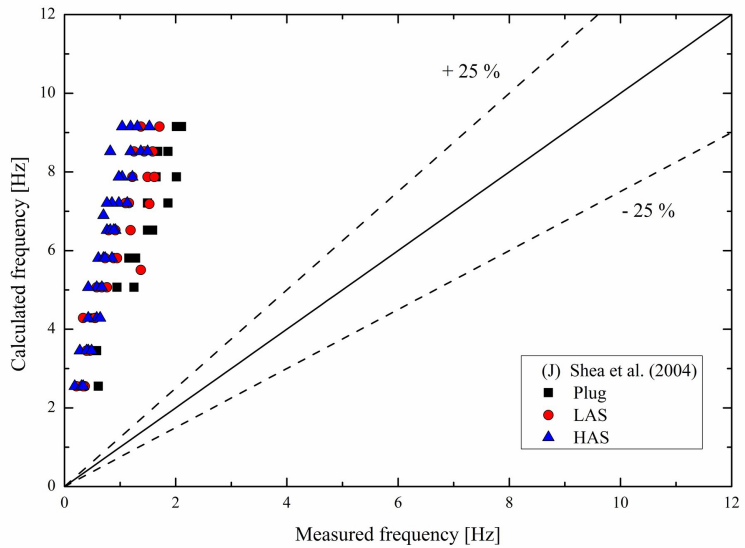




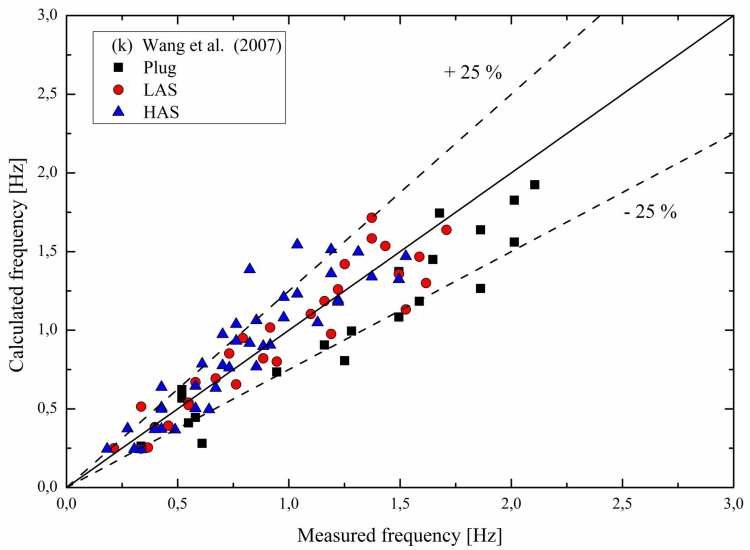




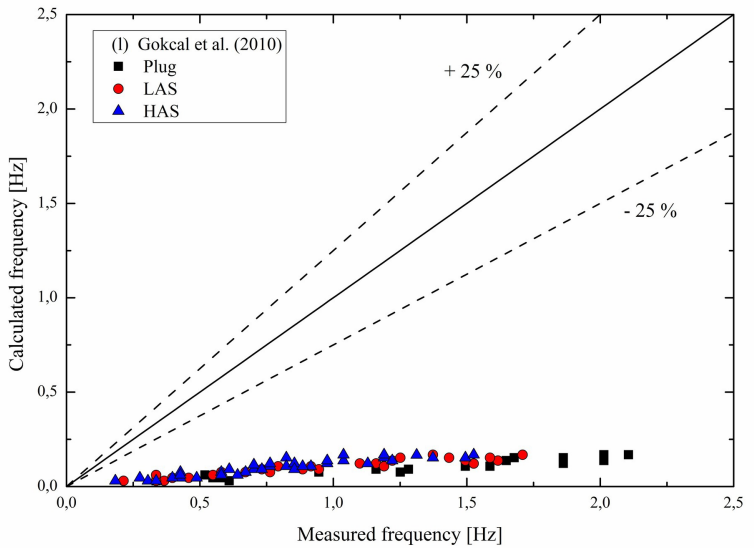




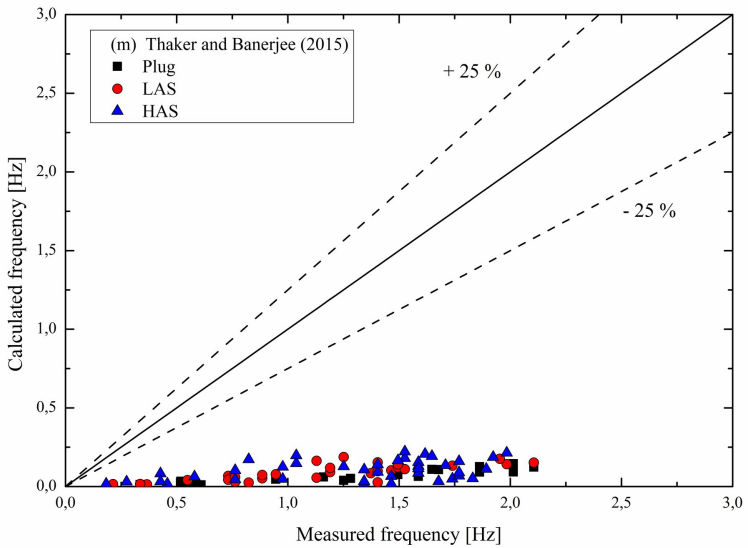




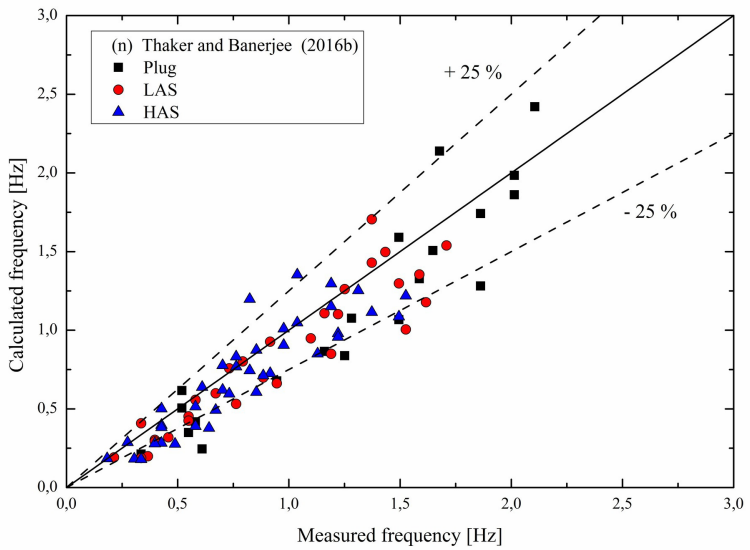




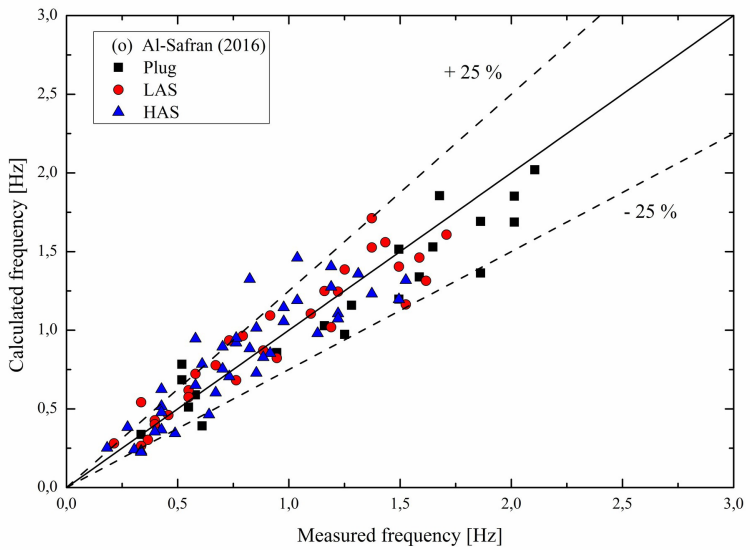




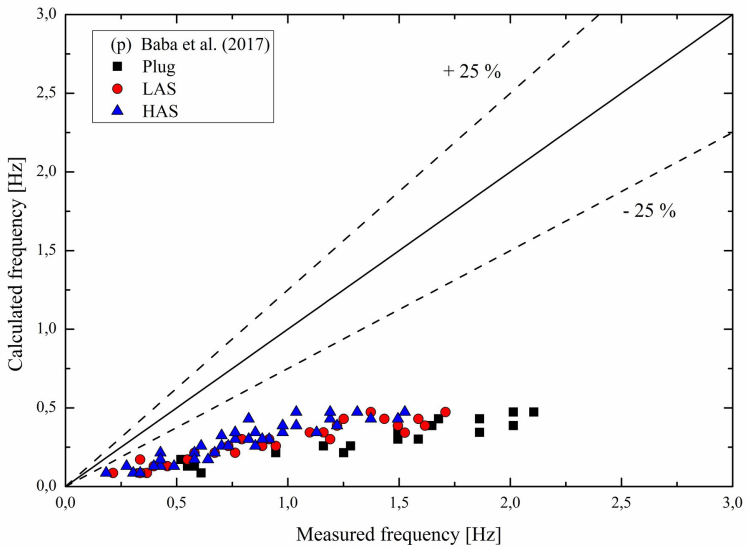




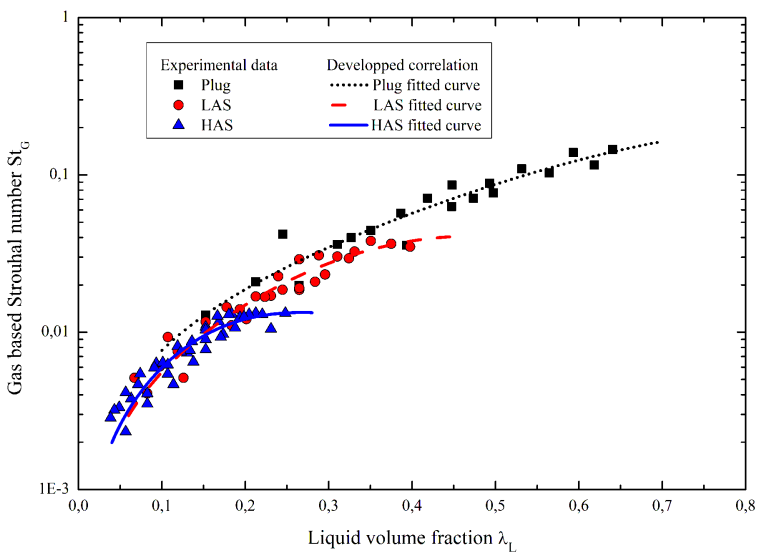




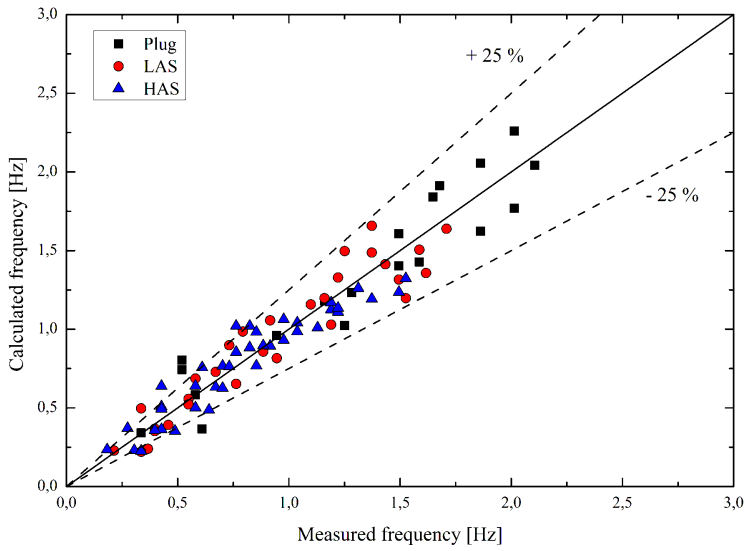




\begin{tabular}{|c|c|c|c|}
\hline $\begin{array}{l}\text { Authors/ } \\
\text { Year }\end{array}$ & Developed Correlation for Slug Frequency & $\begin{array}{l}\text { Diameter of } \\
\text { pipe }\end{array}$ & Working fluids \\
\hline $\begin{array}{c}\text { Gregory } \\
\text { and Scott } \\
(1969)\end{array}$ & $f_{S}=0.0226\left[\frac{V_{S L}}{g D}\left(\frac{19.75}{V_{M}}+V_{M}\right)\right]^{1.2}$ & $\begin{array}{l}0.019 \mathrm{~m} \text { and } \\
0.035 \mathrm{~m}\end{array}$ & $\mathrm{CO}_{2} /$ water \\
\hline $\begin{array}{l}\text { Grescovitch } \\
\text { and Shrier } \\
\quad(1972)\end{array}$ & $f_{S}=0.0226\left[\frac{V_{S L}}{V_{M}}\left(\frac{2.02}{D}+\frac{V_{m}^{2}}{g D}\right)\right]^{1.2}$ & $\begin{array}{l}0.032 \mathrm{~m} \text { and } \\
0.038 \mathrm{~m}\end{array}$ & Air/water \\
\hline $\begin{array}{l}\text { Heywood } \\
\text { and } \\
\text { Richardson } \\
(1979)\end{array}$ & $f_{s}=0.0434\left[\frac{V_{S L}}{V_{M}}\left(\frac{2.02}{D}+\frac{V_{m}^{2}}{g D}\right)\right]^{1.02}$ & $0.042 \mathrm{~m}$ & Air/water \\
\hline $\begin{array}{l}\text { Fetter } \\
(1988)\end{array}$ & $f_{s}=0.0175\left[\frac{V_{S L}}{g D}\left(\frac{21.3+V_{m}^{2}}{V_{m}}\right)\right]^{1.37}$ & - & - \\
\hline $\begin{array}{l}\text { Hill and } \\
\text { Wood } \\
(1990)\end{array}$ & $f_{S}=\frac{0.275}{3600}\left(\frac{V_{M}}{D}\right) \cdot 10^{2.68 H_{L e}}$ & $\begin{array}{l}\text { From } 0.050 \mathrm{~m} \\
\text { to } 0.590 \mathrm{~m}\end{array}$ & $\begin{array}{l}\text { Various fluids, } \\
\text { not } \\
\text { communicate }\end{array}$ \\
\hline $\begin{array}{l}\text { Nydal et al. } \\
\quad(1992)\end{array}$ & $f_{s}=0.088 \frac{\left(V_{S L}+1.5\right)^{2}}{g D}$ & $\begin{array}{l}0.053 \mathrm{~m} \text { and } \\
0.09 \mathrm{~m}\end{array}$ & Air/water \\
\hline $\begin{array}{l}\text { Jepson and } \\
\text { Taylor } \\
\text { (1993) }\end{array}$ & $f_{S}=\frac{V_{S L}}{D}\left(0.00759 V_{M}+0.01\right)$ & $0.3 \mathrm{~m}$ & Air/water \\
\hline \multirow{3}{*}{$\begin{array}{l}\text { Hill and } \\
\text { Wood } \\
(1994)\end{array}$} & $f_{S}=\frac{f^{\prime}}{3600}\left(\frac{V_{M}}{D}\right) \frac{1}{\left(1-0.05 V_{S G}\right) D^{0.3}}$ & \multirow{3}{*}{$\begin{array}{l}\text { Same datas } \\
\text { Hill and } \\
\text { Wood (1990) }\end{array}$} & \multirow{3}{*}{$\begin{array}{l}\text { Same datas Hill } \\
\text { and Wood } \\
\text { (1990) }\end{array}$} \\
\hline & $f^{\prime}=-24.729+0.00766 e^{9.91209 H_{L e}^{*}}+24.721 e^{0.20524 H_{L e}^{*}}$ & & \\
\hline & $H_{L e}^{*}=H_{L e}\left(1-\frac{0.000}{V_{S L}}\right)$ & & \\
\hline \multirow[t]{2}{*}{$\begin{array}{l}\text { Manolis et } \\
\text { al. (1995) }\end{array}$} & $\begin{array}{c}f_{S}=0.0037 F r_{\bmod }^{1.8} \\
F r_{\text {mod }}=\frac{V_{S L}}{g D}\left(\frac{V_{M \cdot \min }^{2}+V_{M}^{2}}{V_{M}}\right)\end{array}$ & \multirow[t]{2}{*}{$0.078 \mathrm{~m}$} & \multirow[t]{2}{*}{ Air/water } \\
\hline & $V_{M . \min }=5 \mathrm{~m} / \mathrm{s}$ & & \\
\hline $\begin{array}{l}\text { Silva et al. } \\
\quad(1997)\end{array}$ & $f_{s}=0.0148 \frac{V_{S L}}{g D}\left[\frac{20.308}{V_{m}}+1.3436 V_{m}\right]^{1.2879}$ & $0.0444 \mathrm{~m}$ & Air/water \\
\hline \multirow[t]{2}{*}{$\begin{array}{l}\text { Cai et al. } \\
(1999)\end{array}$} & $f_{S}=K_{\theta}\left[\frac{V_{S L}}{g D}\left(\frac{36}{1.25 V_{M}}+1.25 V_{M}\right)\right]^{1.2}$ & \multirow[t]{2}{*}{$0.100 \mathrm{~m}$} & \multirow[t]{2}{*}{$\begin{array}{l}\text { Air/water } \\
\mathrm{CO}_{2} / \text { water }\end{array}$} \\
\hline & $K_{\theta}=0.018 * e^{\sin \theta}$ & & \\
\hline \multirow{3}{*}{$\begin{array}{l}\text { Shell slug } \\
\text { frequency } \\
\text { correlation }\end{array}$} & $\begin{array}{l}f_{S} \\
=\sqrt{\frac{g}{D}\left[0.048 F r_{L}^{0.81}+0.73 F r_{L}^{2.34}\left(\left(F r_{L}+F r_{G}\right)^{0.1}-1.17 F r_{L}^{0.064}\right)^{2}\right]}\end{array}$ & \multirow{3}{*}{$\begin{array}{l}\text { Not } \\
\text { communicated }\end{array}$} & \multirow{3}{*}{$\begin{array}{l}\text { Not } \\
\text { communicated }\end{array}$} \\
\hline & $F r_{L}=V_{S L} / \sqrt{g D}$ & & \\
\hline & $F r_{G}=V_{S G} / \sqrt{g D}$ & & \\
\hline $\begin{array}{c}\text { Zabaras } \\
(2000)\end{array}$ & $f_{S}=0.0226\left[\frac{V_{S L}}{g D}\left(\frac{19.75}{V_{M}}+V_{M}\right)\right]^{1.2} *(0.836+2.75 \sin \theta)$ & $\begin{array}{l}\text { From } 0.025 \mathrm{~m} \\
\text { to } 0.203 \mathrm{~m}\end{array}$ & Air/water \\
\hline \multirow{3}{*}{$\begin{array}{l}\text { Fossa et al. } \\
\quad(2003)\end{array}$} & $S t_{G}=\frac{0.044 \lambda_{L}}{1-1.71 \lambda_{L}+0.70 \lambda_{L}^{2}}$ & \multirow{3}{*}{$\begin{array}{c}0.019 \mathrm{~m}, 0.04 \\
\mathrm{~m}, 0.042 \mathrm{~m} \\
0.06 \mathrm{~m}, \\
0.0763 \mathrm{~m} \\
0.095 \mathrm{ùm} \\
\text { and } 0.150 \mathrm{~m}\end{array}$} & \multirow{3}{*}{ Air/water } \\
\hline & $S t_{G}=\frac{F_{S} D}{V_{s g}}$ & & \\
\hline & $\lambda_{L}=\frac{V_{S L}}{V_{S L}+V_{S G}}$ & & \\
\hline $\begin{array}{l}\text { Shea et al. } \\
\text { (2004) }\end{array}$ & $f_{s}=\frac{0.47 V_{S L}^{0.75}}{D^{1.2} L_{p}^{0.55}}$ & $\begin{array}{l}\text { Not } \\
\text { communicated }\end{array}$ & $\begin{array}{l}\text { Not } \\
\text { communicated }\end{array}$ \\
\hline
\end{tabular}




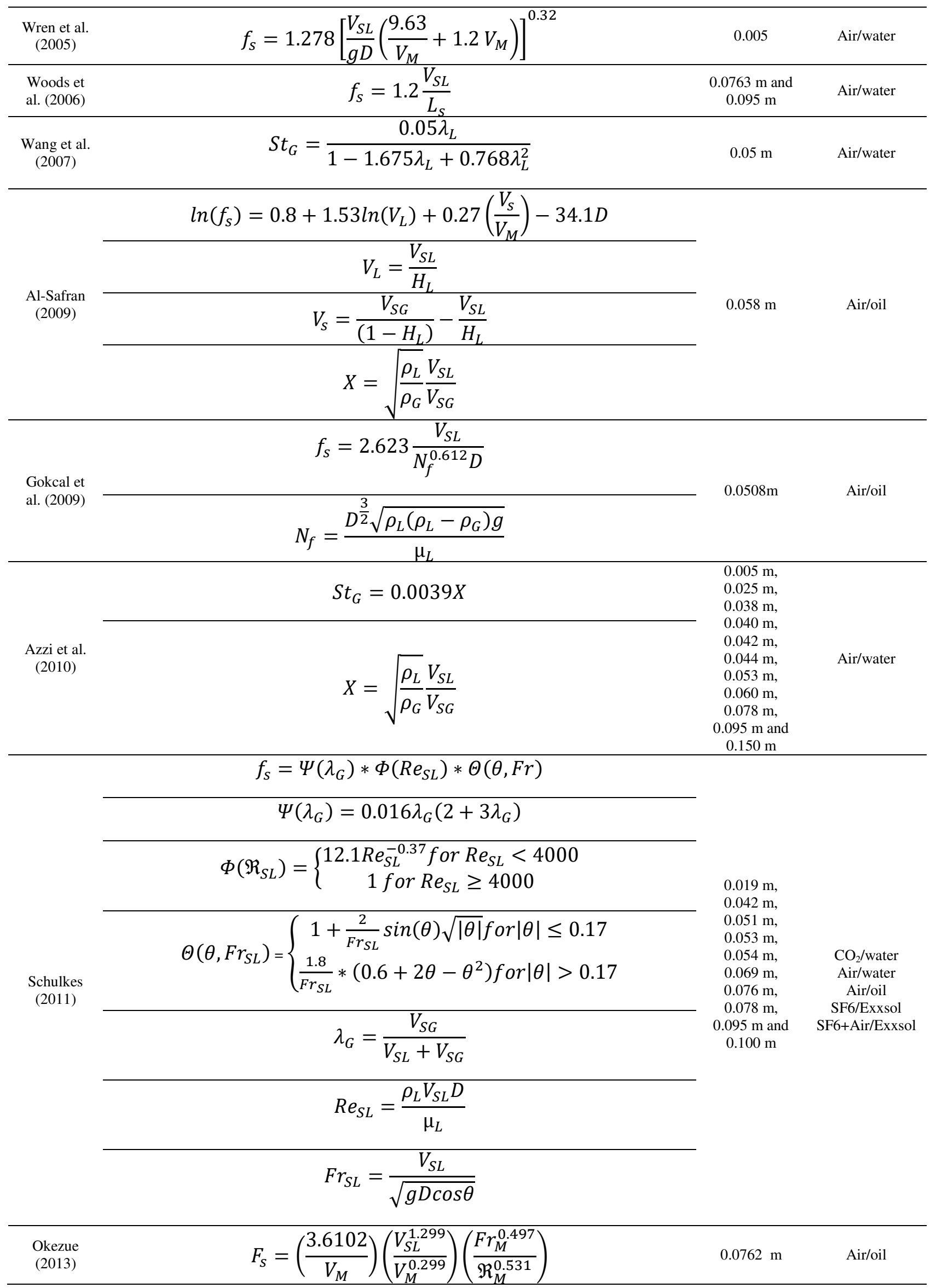




\begin{tabular}{|c|c|c|c|}
\hline \multirow{3}{*}{$\begin{array}{l}\text { Zhao et al. } \\
\text { (2013) }\end{array}$} & $\frac{f_{S}}{\Psi(\alpha)}=\left\{\begin{array}{c}10.836 R e_{S L}^{-0.337} \text { for } R e_{S G} \leq 4000 \\
6.40 R e_{S L}^{-0.141} \text { for } \operatorname{Re}_{S G}>4000\end{array}\right.$ for $R e_{S L}<4000$ & \multirow{3}{*}{$\begin{array}{l}0.026 \mathrm{~m} \text { and } \\
0.074 \mathrm{~m}\end{array}$} & \multirow{3}{*}{ Air/oil } \\
\hline & $R e_{S G}=\frac{\rho_{G} V_{S G} D}{\mu_{G}}$ & & \\
\hline & $\Psi(\alpha)=0.016 \alpha(2-3 \alpha)$ & & \\
\hline \multirow{3}{*}{$\begin{array}{l}\text { Archibong } \\
\text { (2015) }\end{array}$} & $\begin{array}{c}\ln f_{S}=0.138 \ln \left(F r_{M}\right)-0.801 \ln \left(V_{S G D}\right)+1.661 \ln \left(\lambda_{L}\right) \\
-0.277 \ln \left(M_{R}\right)\end{array}$ & \multirow{3}{*}{$\begin{array}{l}0.025 \mathrm{~m} \text { and } 0 \\
0.0762 \mathrm{~m}\end{array}$} & \multirow{3}{*}{ Air/oil } \\
\hline & $V_{S G D}=\frac{V_{S G}\left[\sqrt{\left[\left(\rho_{L}-\rho_{G}\right) / \rho_{G}\right]}\right]}{\sqrt{g D}}$ & & \\
\hline & $M_{R}=\frac{R e_{S L} V_{S L}^{2}}{R e_{S G} V_{S G}^{2}}$ & & \\
\hline $\begin{array}{l}\text { Vicencio } \\
\text { and al. } \\
(2015) \\
\end{array}$ & $f_{S}=0.08 \frac{V_{S L}}{D}\left(\frac{V_{S L}}{V_{S G}}\right)^{0.45}$ & $0.0258 \mathrm{~m}$ & Air/water \\
\hline $\begin{array}{c}\text { Thaker and } \\
\text { Banerjee } \\
\text { (2015) }\end{array}$ & $f_{S}=1.5210^{-8}\left(\frac{L_{p}}{D}\right)^{-0.14}\left(R e_{S L}\right)^{1.45}\left(R e_{S G}\right)^{0.28}$ & $0.025 \mathrm{~m}$ & Air/water \\
\hline \multirow{2}{*}{$\begin{array}{l}\text { Thaker and } \\
\text { Banerjee } \\
(2016 \mathrm{~b})\end{array}$} & $S t_{M}=\frac{0.036 \lambda_{L}}{1-1.432 \lambda_{L}+0.739 \lambda_{L}^{2}}$ & \multirow[t]{2}{*}{$0.025 \mathrm{~m}$} & \multirow[t]{2}{*}{ Air/water } \\
\hline & $S t_{M}=\frac{F_{S} D}{V_{M}}$ & & \\
\hline \multirow{3}{*}{$\begin{array}{l}\text { Al-Safran } \\
(2016)\end{array}$} & $\ln f_{S}=\left[1.51-17.04 D+0.77 \ln \left(V_{S L}\right)-0.181 \ln (S)\right]$ & \multirow{3}{*}{$\begin{array}{c}0.025 \mathrm{~m} \\
0.051 \mathrm{~m} \\
0.076 \mathrm{~m} \\
0.178 \mathrm{~m} \text { and } \\
0.203 \mathrm{~m}\end{array}$} & \multirow{3}{*}{$\begin{array}{c}\text { Air/water, } \\
\text { Air/oil, } \\
\text { Air/Kerosene, } \\
\text { Air/mineral oil, } \\
\text { Freon/ water } \\
\text { and } \\
\mathrm{N}_{2} / \text { diesel }\end{array}$} \\
\hline & $S=\frac{V_{G}}{V_{L}}=1+1.95\left(\frac{\mu_{L}}{\mu_{0}}\right)^{0.01}\left(\frac{V_{S G}}{V_{S L}}\right)^{1.5}$ & & \\
\hline & $\mu_{0}=1$ Pa.s, reference viscosity & & \\
\hline $\begin{array}{l}\text { Abdulkadir } \\
\text { et al. } \\
(2016) \\
\end{array}$ & $S t_{G}=0.184 \lambda_{L}^{1.274}$ & $0.067 \mathrm{~m}$ & Air/Silicone Oil \\
\hline $\begin{array}{l}\text { Baba and } \\
\text { al. (2017) }\end{array}$ & $f_{S}=1.8102 \frac{V_{S L}}{N_{f}^{-0.4687} D}$ & $0.0762 \mathrm{~m}$ & Air/ oil \\
\hline \multirow{3}{*}{$\begin{array}{l}\text { Archibong- } \\
\text { Eso et al. } \\
\text { (2017) }\end{array}$} & $\ln f_{S}=\beta \ln \left[\frac{\lambda_{L}}{\varphi^{n}}\right]$ & \multirow{3}{*}{$\begin{array}{c}0.023 \mathrm{~m}, \\
0.025 \text { and } \\
0.076 \mathrm{~m}\end{array}$} & \multirow{3}{*}{ Air/oil } \\
\hline & $\varphi=\left[\frac{D^{\frac{3}{2}} \sqrt{\rho_{L}\left(\rho_{L}-\rho_{G}\right) g}}{\mu_{L}}\right]$ & & \\
\hline & $(\beta, n)=\left\{\begin{array}{l}(0.75,0.55) \text { for } R e_{S G} \leq 2500 \\
(0.35,1.02) \text { for } R e_{S G}>2500\end{array}\right.$ & & \\
\hline
\end{tabular}




\begin{tabular}{lcc}
\hline Parameter & Operating conditions & Accuracy \\
\hline Pipe diameter & $0.03 \mathrm{~m}$ & $\pm 0.00005 \mathrm{~m}$ \\
Rate of liquid flow & $3-331 / \mathrm{mn}$ & $\pm 0.661 / \mathrm{mn}$ \\
Rate of gas flow & $18.5-1501 / \mathrm{mn}$ & $\pm 1.57 \mathrm{l} / \mathrm{mn}$ \\
Superficial velocity of liquid & $0.141-0.778 \mathrm{~m} / \mathrm{s}$ & $\pm 0.012 \mathrm{~m} / \mathrm{s}$ \\
Superficial velocity of gas & $0.436-3.537 \mathrm{~m} / \mathrm{s}$ & $\pm 0.089 \mathrm{~m} / \mathrm{s}$ \\
Pressure drop & $-10000-10000 \mathrm{~Pa}$ & $\pm 200 \mathrm{~Pa}$ \\
\hline
\end{tabular}




\begin{tabular}{|c|c|c|c|c|c|c|c|}
\hline Auteurs & Fluid system & $\begin{array}{l}\text { Diameter of } \\
\text { pipe }[\mathrm{m}]\end{array}$ & $\mathrm{V}_{\mathrm{SL}}$ range $[\mathrm{m} / \mathrm{s}]$ & $\mathrm{V}_{\mathrm{SG}}$ range $[\mathrm{m} / \mathrm{s}]$ & $\begin{array}{c}\text { Slug } \\
\text { Frequency } \\
\text { range }[\mathrm{Hz}]\end{array}$ & $\begin{array}{l}\text { Datas } \\
\text { points }\end{array}$ & $\begin{array}{c}\text { Number of } \\
\text { zones }\end{array}$ \\
\hline $\begin{array}{c}\text { Woods and } \\
\text { Hanratty (1999) }\end{array}$ & Air/water & $0.0763 \mathrm{~m}$ & $0.1-1.2$ & $1-6.194$ & $\begin{array}{c}0.030- \\
1.078\end{array}$ & 57 & 3 \\
\hline $\begin{array}{c}\text { Thaker and } \\
\text { Banerjee (2016a) }\end{array}$ & Air/water & $0.025 \mathrm{~m}$ & $0.194-0.971$ & $0.484-3.388$ & $\begin{array}{l}0.21- \\
3.206\end{array}$ & 54 & 3 \\
\hline $\begin{array}{l}\text { Dinaryanto et al. } \\
\text { (2017) }\end{array}$ & Air/water & $0.026 \mathrm{~m}$ & $0.2-0.77$ & $0.943-6.202$ & $\begin{array}{c}0.261- \\
2.110\end{array}$ & 20 & 4 \\
\hline Present study & Air/water & $0.030 \mathrm{~m}$ & $0.141-0.778$ & $0.436-3.536$ & $\begin{array}{c}0.183- \\
2.106 \\
\end{array}$ & 90 & 3 \\
\hline
\end{tabular}




\begin{tabular}{|c|c|c|c|c|}
\hline Correlation & $\begin{array}{l}\text { Statistical } \\
\text { parameter }\end{array}$ & Plug Flow & LAS & HAS \\
\hline Gregory and Scott & $\mathrm{F}$ & 0.959 & 1.092 & 1.169 \\
\hline (1969) & $\mathrm{S}$ & 0.118 & 0.090 & 0.117 \\
\hline Greskovitch and Shrier & $\mathrm{F}$ & 0.882 & 0.950 & 0.973 \\
\hline (1972) & S & 0.128 & 0.091 & 0.091 \\
\hline Heywood and & $\mathrm{F}$ & 0.927 & 1.009 & 1.056 \\
\hline Richardson (1979) & $\mathrm{S}$ & 0.129 & 0.094 & 0.096 \\
\hline \multirow{2}{*}{ Fetter (1988) } & $\mathrm{F}$ & 0.802 & 0.955 & 1.050 \\
\hline & $\mathrm{S}$ & 0.118 & 0.104 & 0.148 \\
\hline \multirow{2}{*}{ Nydal et al. (1992) } & $\mathrm{F}$ & 0.992 & 0.862 & 0.811 \\
\hline & $S$ & 0.180 & 0.181 & 0.152 \\
\hline \multirow{2}{*}{$\begin{array}{l}\text { Jepson and Taylor } \\
\text { (1993) }\end{array}$} & $\mathrm{F}$ & 1.934 & 1.431 & 1.171 \\
\hline & $\mathrm{S}$ & 0.114 & 0.140 & 0.080 \\
\hline \multirow{2}{*}{ Manolis et al. (1995) } & $\mathrm{F}$ & 0.740 & 0.986 & 1.164 \\
\hline & $\mathrm{S}$ & 0.150 & 0.176 & 0.245 \\
\hline \multirow{2}{*}{ Zabaras (2000) } & $\mathrm{F}$ & 1.035 & 1.180 & 1.264 \\
\hline & $S$ & 0.118 & 0.090 & 0.117 \\
\hline \multirow{2}{*}{ Fossa et al. (2003) } & $\mathrm{F}$ & 1.118 & 1.055 & 1.023 \\
\hline & $\mathrm{S}$ & 0.107 & 0.080 & 0.096 \\
\hline \multirow{2}{*}{ Shea et al. (2004) } & $\mathrm{F}$ & 0.495 & 0.433 & 0.404 \\
\hline & $\mathrm{S}$ & 0.109 & 0.115 & 0.090 \\
\hline \multirow{2}{*}{ Wang et al. (2007) } & $\mathrm{F}$ & 1.097 & 1.007 & 0.972 \\
\hline & $\mathrm{S}$ & 0.093 & 0.079 & 0.095 \\
\hline \multirow{2}{*}{ Gokcal et al. (2009) } & $\mathrm{F}$ & 3.015 & 2.619 & 2.459 \\
\hline & $\mathrm{S}$ & 0.090 & 0.079 & 0.086 \\
\hline \multirow{4}{*}{$\begin{array}{l}\text { Thaker et Banerjee } \\
\text { (2015) } \\
\text { Thaker and Banerjee } \\
\text { (2016b) }\end{array}$} & $\mathrm{F}$ & 3.778 & 2.921 & 2.529 \\
\hline & $\mathrm{S}$ & 0.159 & 0.136 & 0.158 \\
\hline & $\mathrm{F}$ & 1.089 & 1.075 & 1.071 \\
\hline & $\mathrm{S}$ & 0.125 & 0.092 & 0.108 \\
\hline \multirow{2}{*}{ Al Safran (2016) } & $\mathrm{F}$ & 1.032 & 0.985 & 0.985 \\
\hline & $\mathrm{S}$ & 0.086 & 0.077 & 0.105 \\
\hline \multirow{2}{*}{ Baba et al. (2017) } & $\mathrm{F}$ & 1.924 & 1.671 & 1.568 \\
\hline & $\mathrm{S}$ & 0.090 & 0.078 & 0.086 \\
\hline
\end{tabular}




\begin{tabular}{cccc}
\hline Coefficients & Plug Flow & LAS & HAS \\
\hline$A$ & 0.06327 & 0.04071 & 0.04234 \\
$B$ & -1.855 & -3.105 & -4.271 \\
$C$ & 1.163 & 4.188 & 13.860 \\
\hline
\end{tabular}




\begin{tabular}{ccccc}
\hline Correlation & $\begin{array}{c}\text { Statistical } \\
\text { parameter }\end{array}$ & Plug Flow & LAS & HAS \\
\hline \multirow{2}{*}{ Proposed correlation } & $\mathrm{F}$ & 0.997 & 1.007 & 1.008 \\
& $\mathrm{~S}$ & 0.089 & 0.082 & 0.085 \\
\hline
\end{tabular}




\begin{tabular}{|c|c|c|c|c|}
\hline Correlation & $\begin{array}{l}\text { Statistical } \\
\text { parameter }\end{array}$ & Plug Flow & LAS & HAS \\
\hline \multirow{6}{*}{$\begin{array}{l}\text { Gregory and Scott } \\
\text { (1969) } \\
\text { Greskovitch and Shrier } \\
\text { (1972) } \\
\text { Heywood and } \\
\text { Richardson (1979) }\end{array}$} & $\mathrm{F}$ & 0.814 & 0.937 & 1.007 \\
\hline & $\mathrm{S}$ & 0.189 & 0.088 & 0.041 \\
\hline & $\mathrm{F}$ & 0.753 & 0.835 & 0.857 \\
\hline & $\mathrm{S}$ & 0.220 & 0.120 & 0.084 \\
\hline & $\mathrm{F}$ & 0.792 & 0.899 & 0.941 \\
\hline & $\mathrm{S}$ & 0.227 & 0.125 & 0.089 \\
\hline \multirow{2}{*}{ Fetter (1988) } & $\mathrm{F}$ & 0.669 & 0.793 & 0.876 \\
\hline & $\mathrm{S}$ & 0.164 & 0.068 & 0.023 \\
\hline \multirow{2}{*}{ Nydal et al. (1992) } & $\mathrm{F}$ & 0.865 & 0.819 & 0.763 \\
\hline & $\mathrm{S}$ & 0.272 & 0.227 & 0.234 \\
\hline \multirow{2}{*}{$\begin{array}{l}\text { Jepson and Taylor } \\
\text { (1993) }\end{array}$} & $\mathrm{F}$ & 1.629 & 1.339 & 1.075 \\
\hline & $\mathrm{S}$ & 0.093 & 0.065 & 0.092 \\
\hline \multirow{2}{*}{ Manolis et al. (1995) } & $\mathrm{F}$ & 0.590 & 0.737 & 0.897 \\
\hline & $\mathrm{S}$ & 0.114 & 0.138 & 0.115 \\
\hline \multirow{2}{*}{ Zabaras (2000) } & $\mathrm{F}$ & 0.880 & 1.013 & 1.088 \\
\hline & $\mathrm{S}$ & 0.189 & 0.088 & 0.041 \\
\hline \multirow{2}{*}{ Fossa et al. (2003) } & $\mathrm{F}$ & 0.942 & 0.932 & 0.909 \\
\hline & $\mathrm{S}$ & 0.060 & 0.028 & 0.050 \\
\hline \multirow{2}{*}{ Shea et al. (2004) } & $\mathrm{F}$ & 0.484 & 0.454 & 0.423 \\
\hline & $\mathrm{S}$ & 0.189 & 0.140 & 0.147 \\
\hline \multirow{2}{*}{ Wang et al. (2007) } & $\mathrm{F}$ & 0.929 & 0.896 & 0.865 \\
\hline & $\mathrm{S}$ & 0.088 & 0.036 & 0.054 \\
\hline \multirow{2}{*}{ Gokcal et al. (2009) } & $\mathrm{F}$ & 2.386 & 2.214 & 2.063 \\
\hline & $\mathrm{S}$ & 0.124 & 0.071 & 0.077 \\
\hline \multirow{4}{*}{$\begin{array}{l}\text { Thaker et Banerjee } \\
(2015) \\
\text { Thaker and Banerjee } \\
(2016 b)\end{array}$} & $\mathrm{F}$ & 4.020 & 3.321 & 2.843 \\
\hline & $\mathrm{S}$ & 0.074 & 0.067 & 0.062 \\
\hline & $\mathrm{F}$ & 0.914 & 0.932 & 0.938 \\
\hline & $\mathrm{S}$ & 0.043 & 0.020 & 0.030 \\
\hline \multirow{2}{*}{ Al Safran (2016) } & $\mathrm{F}$ & 0.918 & 0.917 & 0.919 \\
\hline & $\mathrm{S}$ & 0.128 & 0.067 & 0.067 \\
\hline \multirow{2}{*}{ Baba et al. (2017) } & $\mathrm{F}$ & 1.549 & 1.436 & 1.338 \\
\hline & $\mathrm{S}$ & 0.124 & 0.071 & 0.078 \\
\hline \multirow{2}{*}{ Present correlation } & $\mathrm{F}$ & 0.919 & 0.999 & 1.027 \\
\hline & $\mathrm{S}$ & 0.120 & 0.092 & 0.163 \\
\hline
\end{tabular}




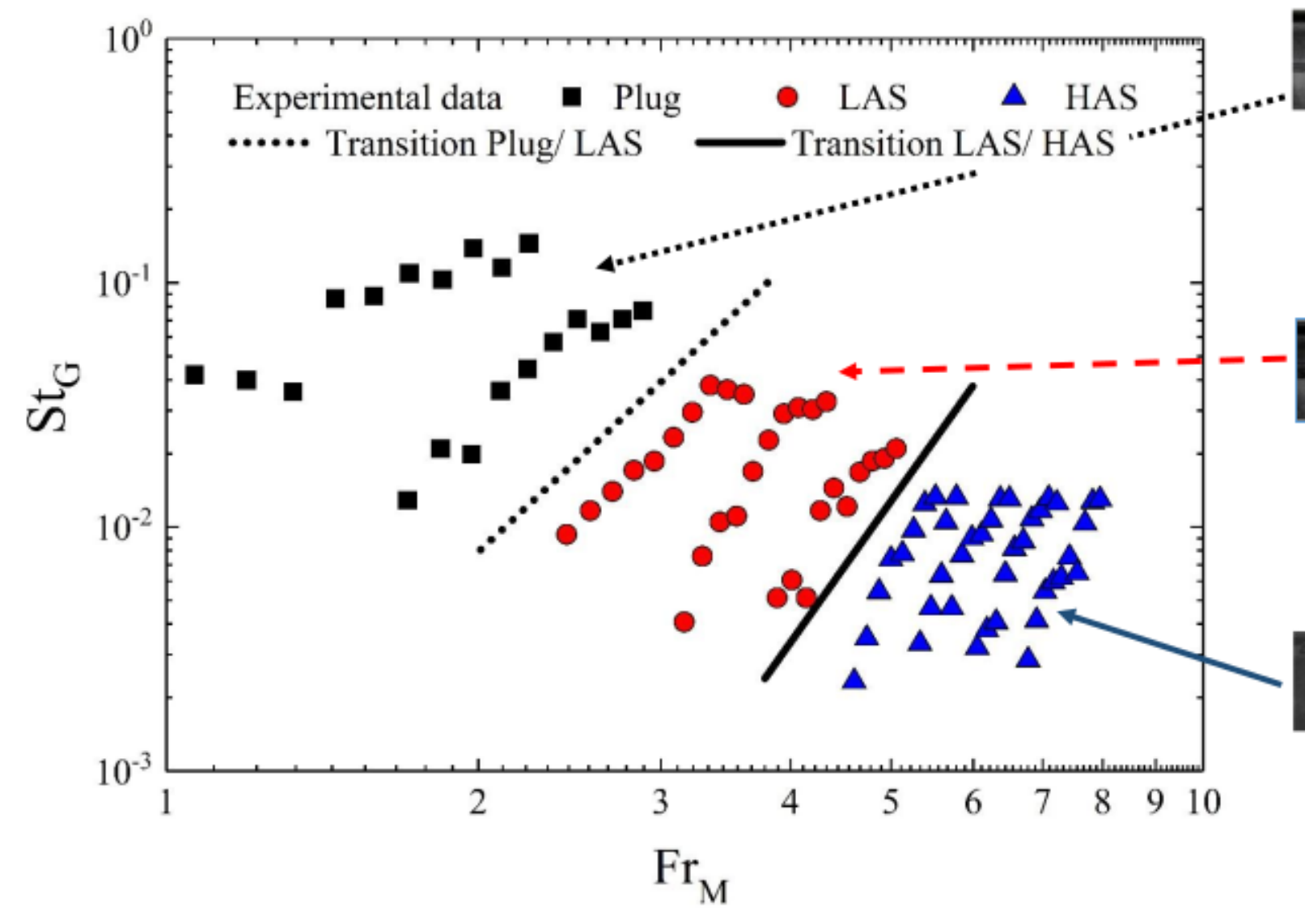

\section{Plug flow}

Less Aerated Slug flow (LAS)

Highly Aerated Slug flow (HAS)

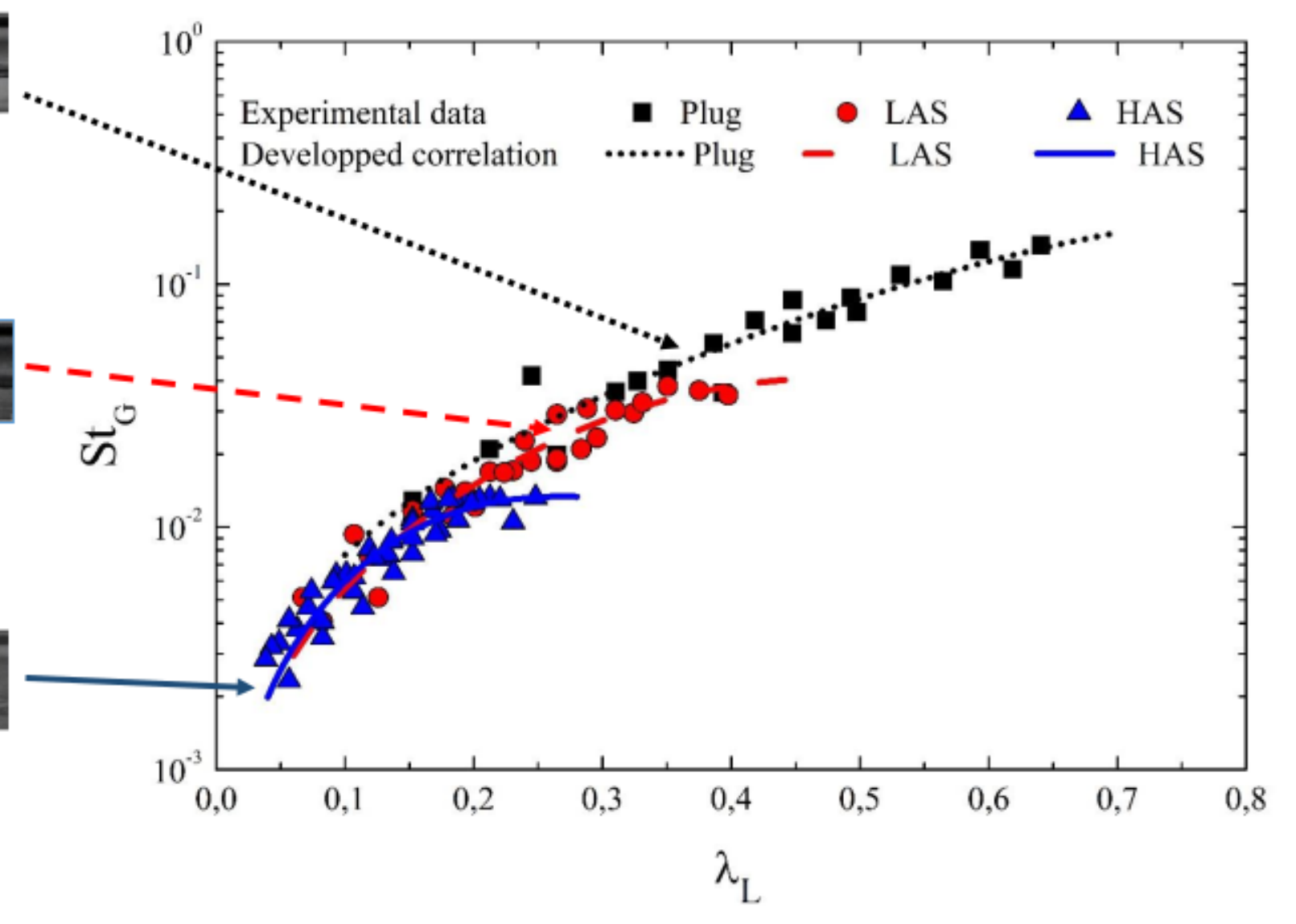

